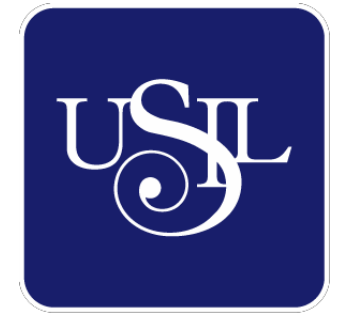

UNIVERSIDAD

SAN IGNACIO

DE LOYOLA

FACULTAD DE DERECHO

Carrera de Relaciones Internacionales

\title{
DIFICULTADES DE UNA POLÍTICA COMÚN EN LA UNIÓN EUROPEA ANTE LA CRISIS DE LOS REFUGIADOS, 2015 - 2017
}

Tesis para optar el Título Profesional de Licenciado en Relaciones Internacionales

\section{JAIME CRISTHIAN VELASQUEZ CABRERA 0000-0002-8754-2763}

Asesor:

Francisco Belaunde Matossian

0000-0003-0762-5460

Lima - Perú

2020 
Índice

Capítulo I: Introducción

1. Introducción 6

1.1. Situación Problemática 6

1.2. Formulación del Problema

1.3. Justificación de la Investigación $\quad 7$

1.4. Objetivos 9

1.4.1. Objetivo General 9

1.4.2. Objetivos Específicos 9

Capítulo II: Marco Teórico

2. Marco Teórico 10

2.1. Antecedentes 10

2.2. Marco Teórico 11

Capítulo III: Metodología de la Investigación

3. Metodología de la Investigación $\quad 17$

3.1. Tipo de Investigación $\quad 17$

3.2. Diseño de la Investigación 17

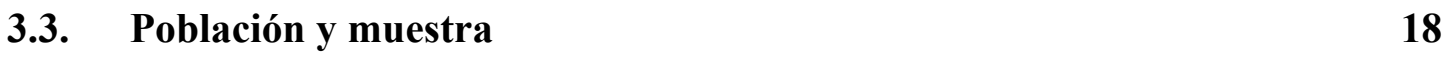

$\begin{array}{lll}\text { 3.4. } & \text { Recolección de datos } & 18\end{array}$

Capítulo IV: Investigación

4. Investigación 20

4.1. Construcción de la Integración Europea $\quad 20$

4.2. Los refugiados en el Sistema Internacional 27

4.3. Crisis de los Refugiados impacto en la Unión Europea 33

Capítulo V: Resultados de la Investigación

5. Resultados de la Investigación $\quad 42$

5.1. Factores Políticos y Sociales 43

Capítulo VI: Conclusiones y Recomendaciones

$\begin{array}{ll}\text { 6. Conclusiones } & 65\end{array}$

$\begin{array}{lll}\text { 7. } & \text { Recomendaciones } & 68\end{array}$

$\begin{array}{ll}\text { Referencias Bibliográficas } & 72\end{array}$ 
DIFICULTADES DE UNA POLÍTICA COMUN EN EUROPA ANTE LA CRISIS DE LOS REFUGIADOS

\section{Dedicatoria}

El presente trabajo de investigación lo dedico en primer lugar a Dios por darme vida, saludy sabiduría durante mi carrera universitaria.

A mis padres por darme la oportunidad de estudiar, que se que se esforzaron mucho por darme una educación de calidad, por siempre hacerme perseverar en las metas que me propongo en la vida.

Agradecer a mis maestros que me instruyeron de la mejor forma para ser un profesional capacitado. 


\section{Resumen}

Desde el año 2015 se ha podido presenciar un gran desplazamiento de habitantes hacia territorio europeo, este flujo migratorio no se había visto desde la Segunda Guerra Mundial. Las políticas existentes de la Unión Europea para hacerle frente al flujo migratorio no estaban hechas para las dimensiones del flujo que se suscito desde el año 2015 por lo que un replanteamiento en las políticas existentes era necesario, para poder preservar el bienestar común en los países miembros de la Unión Europea.

En esta tesis nos enfocaremos en reconocer las dificultades que tiene el bloque para adoptar políticas comunes que ayuden a hacerle frente a la crisis, esto con una investigación sobre las bases de la Unión Europea, los efectos que ha tenido en la política y la sociedad europea y también la repercusión en el Sistema Internacional.

Las dificultades en la adopción de políticas comunes para hacerle frente a la crisis de los refugiados giran también en torno a las diferentes realidades y capacidades que tienen sus actores principales, en este caso los países que forman parte de la Unión Europea, para poder adoptar dichas medidas que implementa el bloque.

El trabajo cuenta con 6 capítulos:

1. Introducción: Introducción de la Investigación

2. Marco Teórico: bases teóricas y conceptos claves

3. Metodología de la Investigación: La teoría aplicada a la investigación

4. Investigación: La implementación de la Metodología

5. Resultados de la Investigación: Análisis de los factores políticos y sociales

6. Conclusiones y Recomendaciones: Análisis critico de la investigación. 


\begin{abstract}
Since 2015 it has been possible to witness a great displacement of inhabitants towards European territory, this migratory flow had not been seen since the Second World War. The existing policies of the European Union to deal with the migratory flow were not made for the dimensions of the flow that arose since 2015, so a rethinking of the existing policies was necessary, in order to preserve the common welfare in the member countries of the European Union.

In this thesis we will focus on recognizing the difficulties that the UE have to adopt common policies that help to face the crisis, this with an investigation on the foundations of the European Union, the effects it has had on European politics and society and also the impact on the International System.

The difficulties in adopting common policies to deal with the refugee crisis also revolve around the different realities and capacities that its main actors have, in this case the countries that are part of the European Union, to be able to adopt these measures that the block implements.

The work has 6 chapters: Introduction, Theoretical Framework, Research Methodology, Research, Research Results, Conclusions and Recommendations.

1. Introduction: Research Introduction

2. Theoretical Framework: theoretical bases and key concepts

3. Research Methodology: Theory applied to research

4. Research: The Implementation of the Methodology

5. Research Results: Analysis of political and social factors

6. Conclusions and Recommendations: Critical analysis of the investigation
\end{abstract}




\section{CAPÍTULO I: FUNDAMENTOS DE LA INVESTIGACIÓN}

\section{Introducción}

La presente investigación nos expone un escenario complejo, el que se vive en Europa como causa de la crisis de los refugiados, el cual ha tenido como efecto escollos en la Unión Europea puesto que, los países no han podido adoptar una política común para darle solución a esta problemática, esto debido a que los actores no se encuentran dispuestos a suprimir su soberanía por completo, un aspecto claro y que ha quedado evidenciado es el de la migración.

En la presente investigación observaremos el desarrollo de la crisis, cuales son sus causas, las medidas que se decidieron adoptar y el método de investigación que se eligió para acceder a la información mas relevante y que concuerde con las metas de la presente tesis. Se hará un análisis critico en el que se usaran fuentes de teoría de Relaciones Internacionales.

\subsection{Situación Problemática}

La situación problemática gira en torno a la masiva llegada de refugiados a territorio de la Unión Europea de forma ilegal, lo que ha evidenciado los desafíos del proyecto europeo. Las crisis migratorias no son nuevas para Europa, tras las grandes guerras y otros acontecimientos que se suscitaron a lo largo de los años. No obstante, la crisis de los refugiados es un nuevo capítulo en esta lista de sucesos y quizás uno de los más complejos debido a que este fenómeno incluye un choque de culturas en este caso entre la europea y la musulmana.

The 2015 Migration Crisis represents one of the most complex issues in the recent history of the European Union, literally dividing Europe in to those which will accept the refugees and those which reject them. [La crisis de la migración que comenzó en 2015 representa uno de los 
temas más complejos en la historia reciente de la Unión Europea, dividiendo a Europa en aquellos que aceptan a los refugiados y aquellos que los rechazan.] (Apetroe, 2016, p.122). Cabe resaltar lo que señala Apetroe esto debido a que como la Unión Europea puede adoptar una política común entre sus miembros si estos mismos no tienen un consenso en cuanto a la aceptación o negación hacia los refugiados.

La Crisis de los Refugiados ha tenido un gran impacto en el entorno social, político y económico dentro de los países miembros de la Unión Europea, esto se ha dado gracias a la continua y constante llegada de refugiados a territorio europeo como causa de los incesantes conflictos en sus países de origen.

Europa siempre ha tratado de mostrarse como un bloque unido frente al mundo, pero las carencias que tienen en cuanto se ven afectados los intereses particulares de los actores miembros demuestra que cuando los intereses se contraponen la misión del proyecto europeo flaquea.

\subsection{Formulación del Problema}

Habiendo ya presentado el escenario anterior, el problema de la investigación será el siguiente: ¿Cuáles son los principales factores que imposibilitan la adopción de una política común en la Unión Europea ante la crisis de los refugiados?

\subsection{Justificación de la Investigación}

Actualmente existen muchas investigaciones relacionadas a la crisis de los refugiados, no obstante, el enfoque de esta tesis varia debido a que lo que se busca en particular es comprender 
por que un bloque como la Unión Europea no ha podido adoptar una política común que resuelva esta crisis.

Ayudará a comprender las dificultades por las que atraviesan la mayoría de los organismos de integración cuando se busca la adopción de políticas comunes en temas que pueden o no perjudicar de forma directa o indirecta los intereses particulares de sus miembros.

La presente investigación nos ayudará a saber en qué proporción la crisis de los refugiados podría llegar a afectar a la Unión Europea.

En la actualidad el fenómeno de los refugiados es sumamente importante ya que no solo se desarrolla en Europa sino que se viene desarrollando, hace ya un tiempo, en Latinoamérica con la fuga de Venezolanos buscando refugio en países vecinos como el nuestro, por lo tanto la buena comprensión del tema será importante para poder actuar ante escenarios similares en el globo, además de que observando las conclusiones y recomendaciones que se logren al final del presente estudio, se podrían adecuar a la situación política, social y/o económica actual que atraviesa Latinoamérica.

La viabilidad del proyecto radica en que este se podrá culminar oportunamente gestionando tiempos para el estudio de casos, entrevistas a diferentes especialistas y/o representantes de los actores principales e interpretación de opiniones similares a la de mi proyecto, además gracias al euro barómetro se contará con información relevante y actualizada constantemente, para poder desarrollar opiniones mas exactas y así emitir posibles soluciones a la problemática europea. 


\subsection{Objetivos}

\subsubsection{Objetivo General}

El objetivo de esta investigación es el de identificar los principales factores que imposibilitan la adopción de una política común en la Unión Europea ante la crisis de los refugiados.

\subsubsection{Objetivos Específicos}

- Analizar los pilares de la construcción de la Unión Europea.

- Analizar ciertas políticas adoptadas por parte de los estados miembros de la Unión Europea.

- Identificar las propuestas realizadas por la Unión Europea para darle solución a la crisis de los refugiados.

- Analizar los efectos que ha tenido la crisis de los refugiados en los aspectos políticos, sociales y económicos en la Unión Europea. 


\section{CAPÍTULO 2: MARCO TEÓRICO}

\subsection{Marco Teórico}

\subsubsection{Antecedentes}

El ser humano a través de la historia ha ido evolucionando, con el su entorno social, político y económico. Hemos presenciado las transformaciones en los modelos económicos, el desarrollo de la tecnología, la creación de nuevos modelos políticos, aparición de nuevas culturas y la perseverancia de algunas y por último la religión que siempre ha estado presente en el escenario mundial.

El traslado de las grandes masas ha sido parte de la historia desde hace muchos años, ya que las guerras siempre han existido, por predominancia de alguna cultura, por búsqueda de riquezas, por hacer que una religión preserve por encima de las demás, por temas raciales entre otros. Los flujos migratorios en Europa fueron causados por las guerras entre civilizaciones y también por colonizaciones agrarias como las de Prusia. (Europa)

La Unión Europa ha demostrado que es un bloque de países capaz de surgir y levantarse después de haber quedado devastada, como prueba de ello podemos mencionar: las Guerras Napoleónicas, la guerra de Crimea, la Primera Guerra Mundial, la Segunda Guerra Mundial y la Guerra Fría; el camino fue largo pero se logró la creación de un bloque de países, con una identidad propia y metas comunes que lo han llevado a ser una de las principales potencias en el mundo, con una de las economías más estables y teniendo la organización internacional, con instituciones y una normativa jurídica común, con más éxito.

La creación de la primera Comunidad Europea tuvo como raíz la interdependencia de los países para así poder erradicar los conflictos que se suscitaban en Europa, esto tras una devastadora Segunda Guerra Mundial (CECA). La creación de un mecanismo de integración entre los países 
europeos asomaba como una solución practica en aquel entonces, el grupo de países que decidió ser parte contaban con intereses comunes, decidieron ser parte "de" y así empezó el camino hacia el futuro.

A través de los años llegaron distintos acuerdos que sumaron e implicaron una mayor cesión de soberanía por parte de los Estados.

En la actualidad contamos con nuevos miembros y los intereses de estos miembros tienden a divergir con lo de los miembros con más capacidad económica y estabilidad política., por un lado tenemos al Grupo del Visegrado el cual rechaza en su mayoría todas las políticas que se han propuesto en la Unión Europea, mientras que Alemania apoyó e impulso el sistema de imposición de cuotas de inmigrantes por países entre otros, todo esto ha tenido una gran repercusión en el escenario político con inesperadas apariciones de la extrema derecha en territorio europeo.

\subsubsection{Marco Teórico}

Las bases teóricas de la presente investigación se ven representadas por dos de las más conocidas teorías de las relaciones internacionales: Realismo y Liberalismo. Ambas ayudan a entender la problemática de la investigación la cual engloba las dificultades por parte de la Unión Europea en la implementación de una política común que de fin a esta crisis.

\section{- Liberalismo}

El proyecto de la Unión Europea es una muestra de lo que nos plantea el Liberalismo, este último promueve la Cooperación Internacional, la creación de Organizaciones Internacionales, 
el rol principal de los organismos supranacionales en el Sistema Internacional y la interdependencia para formar lazos que logren la paz. Keohane (1996)

La Cooperación Internacional es parte fundamental del liberalismo, en este el beneficio grupal prima por encima del particular, por lo que frente a una crisis como la que se estudia, la adopción de una política común es vital para la viabilidad del proyecto que plantea la Unión Europea y para la seguridad de sus miembros.

Robert Keohane en su obra "After Hegemony" expone que "la cooperación requiere que las acciones de individuos u organizaciones -que no se hallaban en armonía preexistente- se adecuen mutuamente por medio de un proceso de negociación, al que generalmente se designa coordinación de políticas”. Gran parte del éxito de los países miembros de la Unión Europea consistió en la creación de un sistema común tanto político, económico y social, por lo tanto, es importante para el bloque europeo que la cooperación internacional se fortalezca de forma que se puedan adoptar políticas comunes que ayuden a resolver las crisis que se presenten, en este caso la "crisis de los refugiados".

Robert Keohane en su obra "International Institutions and State Power" señala lo siguiente: "Lo que aduzco es que las acciones estatales dependen, considerablemente, de los acuerdos institucionales prevalecientes.”. Esto denota las claras diferencias entre la Teoría Liberalista y la Teoría Realista. Se puede deducir entonces que el pensamiento Liberalista limita el accionar de los estados mediante los acuerdos internacionales.

Al hablar del Liberalismo es necesario mencionar a Joseph Nye y Robert Keohane en su obra "Power and Interdependence" en el cual se postulan varias afirmaciones que se acomodan al modelo bajo el que se crearon las raíces de Unión Europea. Y es que para Joseph Nye y Robert Keohane la interdependencia consiste en los efectos recíprocos que llegan a tener los estados entre estos mismos frente a cada situación que se presente en el sistema internacional, en el cual 
el costo que puedan llegar a tener estos, frente a cualquier tipo de acontecimiento, debe ser proporcional para ambos.

Además, Joseph Nye y Robert Keohane en su obra "Power and Interdependence" mencionan:

Los gobiernos deben organizarse para manejar el caudal de iniciativas generado por los organismos internacionales. Al definir los problemas prominentes y decidir cuales pueden agruparse, los organismos pueden contribuir a determinar las prioridades gubernamentales, la naturaleza de las comisiones interdepartamentales y otras disposiciones al interior de los gobiernos. (Keohane, 1996)

Es decir, al existir conflictos plenamente identificados estos organismos definirán las prioridades de acción que deberán tomar los gobiernos para afrontar las distintas problemáticas que puedan suscitarse, esto dentro de un marco normativo establecido por el organismo.

\section{- Realismo}

Al hablar de Realismo debemos asociar este término con poder, intereses nacionales y seguridad interna. Estas son las bases de la corriente realista en la que los estados son seres individuales que fundamentan sus acciones en el interés estatal mas no global, además que el rol del estado siempre estará por encima de cualquier organismo internacional.

Por lo tanto, en el realismo los intereses priman por sobre las necesidades externas, el salvaguardar lo que haga prevalecer al estado es lo que dictamina las acciones de los actores, como consecuencia los intereses justificaran el accionar de los estados por encima de lo que obedezca el sistema internacional.

Según Morgenthau (1985), el Realismo tiene seis principios, no obstante, se explicarán los principios que tengan una relación directa con la investigación. El segundo principio habla fundamentalmente de los intereses en termino de poder es decir el Estado debe actuar en base 
a los intereses y a la seguridad nacional, de esta forma la política exterior de los países se empleará de forma efectiva, ¿En que se asocia esto con la investigación? Se asocia de forma directa al papel que desenvuelven los estados miembros de la Unión Europea, al tomar decisiones que busquen más el bienestar nacional que el de la comunidad europea.

En el número tres menciona sobre los intereses nacionales no siempre serán los mismos, si no que estos podrían variar dependiendo la actualidad. Por lo que los intereses siempre se adecuaran a las necesidades y oportunidades a través del tiempo. En la investigación podemos observar que en el caso de Alemania los intereses nacionales guardan relación con la inmigración a diferencia de los países del Visegrado donde la presencia de una ola migratoria grande afectaría su economía.

Como podemos observar el análisis de las teorías nos da una aproximación de la diferencia en el manejo individual por parte de los actores de la Unión Europea, como algunos optan por seguir un aspecto mas realista al sobreponer el rol del estado por encima del sistema internacional.

\section{- Conceptos}

\section{Refugiado:}

Una persona que, debido a fundados temores de ser perseguida por motivos de raza, religión, nacionalidad, pertenencia a determinado grupo social u opiniones políticas, se encuentre fuera del país de su nacionalidad y no pueda o, a causa de dichos temores, no quiera acogerse a la protección de tal país. (Europeas) (OIM 2006) 


\section{Migración Forzosa:}

Término genérico que se utiliza para describir un movimiento de personas en el que se observa la coacción, incluyendo la amenaza a la vida y su subsistencia, bien sea por causas naturales o humanas. (Por ejemplo, movimientos de refugiados y de desplazados internos, así como personas desplazadas por desastres naturales o ambientales, desastres nucleares o químicos, hambruna o proyectos de desarrollo). (OIM 2006)

\section{Migración Irregular}

Desde el punto de vista de los países de destino significa que es ilegal el ingreso, el estadio o el trabajo, es decir, que el migrante no tiene la autorización necesaria ni los documentos requeridos por las autoridades de inmigración para ingresar, residir o trabajar en un determinado país.

Desde el punto de vista de los países de envió la irregularidad se observa en los casos en que la persona atraviesa una frontera internacional sin documentos de viaje o pasaporte valido o no cumple con los requisitos administrativos exigidos para salir del país. (OIM 2006)

\section{Migrantes Radicados}

Extranjeros a quienes se les autoriza permanecer por un periodo bastante largo o ilimitado y potencialmente no sujeto a ninguna limitación con respecto al ejercicio de sus derechos civiles, económicos y sociales. Ejemplo: migrantes por razones laborales, familiares de ascendencia o jubilados extranjeros) (OIM 2006) 


\section{Refugiados Itinerantes}

Refugiados que sin ser regresados directamente al Estado en el cual pueden ser perseguidos, se les niega asilo o no encuentran un Estados que examine su solicitud y, por tanto, son llevados de un país a otro en búsqueda de asilo. (OIM 2006)

\section{Hambruna}

Resultado de una secuencia de procesos y sucesos que reduce la disponibilidad de alimentos o el derecho al alimento, causando un aumento notable y propagado de la morbilidad y mortalidad. (Organización de las Naciones Unidas para la Alimentación y la Agricultura).

\section{Esfera de influencia geográfica}

Área o región que ejerce cierta clase de influencia económica, política o social en otro país o región. No necesariamente debe ser colonia o estar bajo opresión para ser parte de la esfera de influencia geográfica. 


\section{CAPÍTULO 3: METODOLOGÍA DE LA INVESTIGACIÓN}

\subsection{Tipo de Investigación}

El tipo de investigación a realizar en la presente tesis es cualitativo, esto debido a que a través de la revisión de literatura se podrá identificar diferentes maneras de interpretar la información recolectada.

Se podrá estudiar a fondo el fenómeno en el que se ha convertido la crisis de los refugiados en Europa y como es que ha influido en los miembros, por consiguiente, se interpretara el por qué no se ha podido llegar a un consenso en cuanto a que medidas adoptar para enfrentar esta crisis. Se buscará explicar el impacto que ha tenido en la esfera política, económica y social de los países, así como en las bases de la organización y como es que este ha influido en el accionar de los estados, esto debido a que la Unión Europea ha realizado una serie de propuestas de solución temporal mas no definitiva, por consiguiente, los estados han adoptado soluciones individuales obedeciendo a sus intereses particulares.

\subsection{Diseño de la Investigación}

El diseño de la investigación que se empleará en la presente tesis es el de la Teoría Fundamentada, debido a que es sistemática, esto nos ayudara a dar valoraciones del problema central de la investigación como resultado de la recolección de datos. Estableceremos el orden de la investigación lo que nos permitirá abordar todos los aspectos en los que ha influido la crisis de los refugiados dentro de los países de la Unión Europea. 
Esto se logrará investigando y analizando la actualidad de los países, que impactos ha tenido desde sus inicios la crisis, las distintas medidas que se han intentado adoptar, identificar los problemas que han aparecido como consecuencia de este fenómeno, entre otros.

\subsection{Población y muestra}

Se utilizará la muestra de expertos, ya que se entrevistará a especialistas en relaciones internacionales, conflictos en Europa, así como a algunos representantes de los estados miembros en Perú.

\subsection{Recolección de datos}

Los procesos de recolección de datos cualitativos son importantes debido a que estos proporcionaran información relevante, la cual se analizará e interpretará para posteriormente comprender y así responder la pregunta de la investigación, esto con la finalidad de generar conocimiento del tema.

El diseño de instrumentos elegido es el individual escrito personal preparado por razones científicas, ya que abarca el rango de información necesaria a recolectar en el presente trabajo de investigación.

En el proceso de recolección de datos cualitativos se encuentra establecido que los instrumentos no son estandarizados por lo que en la presente investigación se trabajara con múltiples fuentes de datos las cuales serán: entrevistas a especialistas y representantes de países miembros de la Unión Europea en Perú, documentos oficiales de la Unión Europea, datos estadísticos del Euro Barómetro, noticias de diarios, libro e investigaciones afines al tema. Esto ayudará a 
comprender y llegar a explicar por qué hasta el momento no se ha podido adoptar una política común en la Unión Europa para dar solución a esta crisis.

La información se procesará bajo la teoría ya mencionada y se analizara con el fin de hallar los motivos que dificultan en gran o pequeña magnitud la adopción de una política común en la Unión Europea, por lo que los datos, declaraciones, revistas y lecturas que se presenten en el trabajo estarán asociados a este fin. 


\section{CAPÍTULO IV: INVESTIGACIÓN}

La Unión Europea atraviesa una crisis que no pudo ser anticipada por parte del bloque y la cual ha traído consigo un gran reto. Para poder entender las dificultades que atraviesa el bloque para encontrar una política común que pueda hacerle frente a esta problemática expondremos las bases del organismo, esto nos permitirá dar una recomendación final la cual obedecerá a los principios de la Unión Europea.

\subsection{Construcción de la Integración en la Unión Europea}

La integración europea surge de la necesidad de poner fin a las guerras en el continente.

Para alcanzar ese objetivo Robert Schuman, que fue el pionero de lo que hoy es la Unión Europea, expuso la idea de crear la primera comunidad europea, en este caso la CECA, la cual fundamentalmente buscaba el libre comercio del Acero y el Carbón. El resultado de esto fue la primera administración conjunta en Europa, que tuvo como actores a Francia, Alemania, Italia y los países del Benelux (Bélgica, Holanda y Luxemburgo). (UNION EUROPEA, 1950)

En síntesis, se vio al libre comercio y a la libre circulación de las personas como una herramienta de paz, la cual asegure que los conflictos del pasado no vuelvan a ser un problema para el continente.

Por lo tanto, la Integración Europea es un bloque de países que se rigen bajo una normativa y administración común en la que existen políticas comunes en pro del crecimiento económico europeo, estabilidad política, el libre tránsito de los habitantes miembros de la Unión Europea y el fortalecimiento de la cultura europea.

Para tener un alcance más exacto de cómo es que a través de la historia se fueron sentando las bases de la Integración Europea, describiré las primeras instituciones comunes entre los países 
miembros, las cuales como el mundo ha podido apreciar, culminan en la creación de la Unión Europea, posteriormente se le añadieron una serie de modificaciones para optimizar el pleno funcionamiento del Órgano de Internacional.

\section{- Tratado Constitutivo de la Comunidad Europea del Carbón y del Acero (CECA).}

El Tratado Constitutivo de la CECA es considerado como el primer ladrillo de lo que ahora conocemos como la Unión Europea. Pero ¿Por qué especialmente el carbón y el acero? Se eligieron ambos ya que era un mercado de potencial existente en Europa que no había sido del todo explotado por las barreras que existían hasta ese momento pero que gracias a este acuerdo serian eliminadas.

La creación de la Comunidad Europea del Carbón y del Acero (CECA) fue esencial para la formación de la paz en el continente. Se creyó que para llegar a esta tan anhelada paz se necesitaban lazos igual de fuertes que las ambiciones que podría tener cualquier país, por lo tanto, se necesitaba una Europa organizada y conectada mediante bases e instituciones comunes que lleven al desarrollo económico conjunto de los países, además de eliminar rivalidades pasadas entre los países miembros, creando intereses comunes que los lleven a un trabajo en conjunto en pro del bienestar de los participantes.

Centrándonos en el Tratado en sí, lo que se buscaba era la creación de una comunidad en la cual existiera un mercado común, con metas comunes y que cuente con instituciones comunes que contribuyan a la abolición de las barreras comerciales que tenían el Carbón y el Acero, el efecto secundario radicaba en la creación de oportunidades de trabajo entre los habitantes de los países miembros para la reactivación de la economía, la cual se había visto totalmente afectada por los conflictos que se suscitaron en el Viejo Continente. (El acceso al Derecho de la Union Europea, 2017). 


\section{- Tratado de Roma o Constitutivo de la Comunidad Económica Europea}

El Tratado de Roma o del CEE básicamente lo que buscaba era la expansión de la economía entre los seis países miembros del Tratado de la CECA. Lo que se pretendía era eliminar limitaciones aduanales entre los actores de productos como mercancías, personas, servicios y/capitales exceptuando los ya regulados en el tratado anterior.

No obstante, además del crecimiento en los lazos económicos a través de políticas comerciales comunes que ayudaron a eliminar las restricciones de los intercambios internaciones de los actores, también se buscó unificar la política en Europa, pero de una forma amplia.

Se buscaba ampliar los lazos que iniciaron con el Tratado de la CECA, por lo cual en el presente Tratado se creó el Fondo Social Europeo que básicamente iba dirigido a mejorar la calidad de vida de los habitantes a través de la ampliación de posibilidades de empleo; por otro lado se creó el Banco Europeo de Inversiones (BEI) que fue netamente la búsqueda del crecimiento económico de los países del CEE mediante inversiones directas, en resumen se busco enriquecer a los miembros con la contribución de todos, además este tratado ayudo a impulsar la integración europea debido a que las economías a partir de este momento se encontrarían más interrelacionadas. (europea)

\section{- Acuerdo Schengen}

El Acuerdo Schengen se creó con la idea principal de demoler las fronteras internas, y a su vez fortalecer las fronteras externas, para poder asegurar el libre tránsito de los habitantes de los estados pertenecientes al acuerdo y por consiguiente fortalecer las fronteras exteriores para asegurar el bienestar de los habitantes. 
Esta idea inicio entre los países de Alemania y Francia en 1984, ellos fueron los que llevaron esta propuesta al siguiente nivel, el cual fue debatirla y presentarla dentro del Consejo Europeo. Es así como en el año 1985 se firma el "Acuerdo Schengen” entre cinco países europeos los cuales fueron: Francia, Alemania, Bélgica, Luxemburgo y Países Bajos.

No obstante, es hasta 1990 que las disposiciones estipuladas en el Acuerdo Schengen empiezan a realizarse, estas iniciaron con el proceso de expedición de visados y la creación del SIS Schengen, la cual era una base de datos de los miembros.

A través de los años y no es hasta el Tratado de Ámsterdam, que el Acuerdo Schengen es incluido en los estatutos de la Unión Europea, lo cual repercutió de forma favorable en cuanto a la percepción que empezaron a tener los estados que no eran miembros, ya que la lista de países que se fueron sumando años posteriores fue extensa, esto debido al gran desarrollo económico que trajo consigo la eliminación de barreras entre los países que hasta ese entonces pertenecían al área Schengen.

Cabe resaltar que los países miembros del Acuerdo Schengen cuentan con una herramienta especial, la cual les da la capacidad de reinstaurar el control en sus fronteras en caso vean que sus intereses y el de sus ciudadanos se encuentre en peligro.

El Acuerdo Schengen es un tema de suma relevancia en la presente tesis, ya que se encuentra en medio de la controversia gracias a los propósitos de existencia que tiene, el cual es el libre tránsito de personas en Europa. Como ya es mencionado anteriormente, la continua llegada de solicitantes de asilo y refugiados a Europa han ido en aumento como consecuencia de las incesantes guerras en medio oriente, las cuales produjeron la llegada de un gran flujo de personas a Europa que, al no existir un control riguroso en las fronteras exteriores en los primeros años de desarrollo de la crisis pudieron ingresar fácilmente. 


\section{- Tratado de Maastricht o de la Unión Europea}

Es hasta el Tratado de Maastricht que finalmente la idea de la creación de la Unión Europea se hace realidad. El Organismo de Integración se abre paso en el año 1992, utilizando como base acuerdos anteriores y proponiendo nuevas metas en los diferentes aspectos como el económico, político y social. La creación de una Identidad Europea sonaba como una de las principales ideas en la creación de la Unión Europea, el crecimiento en conjunto de los Estados miembros se daría a través de la cooperación internacional y las instituciones comunes que se planteaban. Se estipula en el Tratado de la Unión Europea lo siguiente:

"Promover un progreso económico y social equilibrado y sostenible, principalmente mediante la creación de un espacio sin fronteras interiores." (Unión Europea, 1992). A este se le suma la creación de una moneda única, con el propósito de fortalecer la unión económica y monetaria en el Viejo Continente. Se busca el fortalecimiento de la identidad europea frente al mundo con la creación de una defensa conjunta entre los países miembros, además de crear una ciudadanía conjunta la cual vendría a ser la Ciudadanía de la Unión.

El sueño que inicio con la CECA se logró y es que en el Tratado de la Unión Europea logramos apreciar la unión de los países del Viejo Continente dentro de un órgano que los represente, cree las oportunidades y los vínculos necesarios para la prosperidad de los miembros, los cuales aseguren una vez más que los conflictos pasados no tomen lugar nuevamente.

\section{- Tratado de Ámsterdam}

Cabe resaltar la existencia de este tratado debido a que se convirtió en el eje central de la nueva normativa legal, se acordó la creación de la "ciudadanía perteneciente a la Unión Europea", se 
estipularon nuevas medidas para la integración de nuevos miembros al bloque, además de darle mayor capacidad a los órganos supranacionales de la Unión Europea.

Los Objetivos del Tratado de Ámsterdam:

Afirmar su identidad en el ámbito internacional, en particular mediante la realización de una política exterior y de seguridad común que incluya la definición progresiva de una política de defensa común. Mantener íntegramente el acervo comunitario y desarrollarlo con el fin de examinar la medida en que las políticas y formas de cooperación establecidas en el presente Tratado deben ser revisadas, para asegurar la eficacia de los mecanismos e instituciones comunitarios. Unión Europea (1997).

Básicamente lo que se busca impulsar en el Tratado de Ámsterdam es el rol de la Unión Europea en el sistema internacional, esto gracias a que habían desarrollado una economía fuerte, contaban con una ubicación geográfica estratégica y habían logrado ser el Organismo de Integración más eficiente en el globo.

\section{- Frontex}

El Frontex es una de las Agencias pertenecientes a la Unión Europea, la cual es la encargada de la Guardia de Fronteras y Costas. Al ser una agencia perteneciente a la UE cuenta con la inversión de esta la cual es recaudada por los miembros tanto de la Unión Europea como de los países pertenecientes al Acuerdo de Schengen (FRONTEX).

Además, el FRONTEX cuenta con una estrategia distinta con respecto a los países asociados al espacio Schengen que no forman parte de la UE:

La cooperación con los países no pertenecientes a la UE y asociados al espacio Schengen forman parte integrante del mandato de Frontex y constituye una de las principales prioridades estratégicas de la Agencia. Para garantizar la aplicación de la gestión 
integrada de las fronteras europeas, Frontex crea y mantiene una red de asociaciones con autoridades fronterizas de terceros países, en particular, con los países vecinos de la UE y los países de origen y tránsito de inmigrantes. (FRONTEX)

Frontex nace como una Agencia encargada del control de la libre circulación en el territorio de la Unión Europea y de los que no pertenecen a la misma pero que se encuentran dentro del Acuerdo de Schengen.

En la actualidad la Agencia Frontex ha incrementado sus responsabilidades debido a la evidente vulnerabilidad en las fronteras de la Unión Europea, como consecuencia el protagonismo de la Agencia fue incrementándose debido a la gran ola migratoria que ingresaba a Europa y se trasladaba entre países debido a los insuficientes recursos con los que contaba en ese entonces.

\section{- Tratado de Lisboa}

El Tratado de Lisboa se dio en el año 2007 y modificó ciertos aspectos del Tratado de la Unión Europea (1992) esta tuvo como objetivo básico el siguiente:

La Unión se fundamenta en los valores de respeto de la dignidad humana, libertad, democracia, igualdad, Estado de Derecho y respeto de los derechos humanos, incluidos los derechos de las personas pertenecientes a minorías. Estos valores son comunes a los Estados miembros en una sociedad caracterizada por el pluralismo, la no discriminación, la tolerancia, la justicia, la solidaridad y la igualdad entre mujeres y hombres. Diario oficial de la Unión Europea. (2007)

En concreto se respetarán los derechos de las personas y se dará igualdad a todos los pobladores de la Unión Europea, luchando contra la discriminación, la intolerancia y en pro de la igualdad de género. 
Cabe resaltar que otro suceso importante ocurrió durante este año y es que la Carta de los Derechos Fundamentales de la Unión Europea proclamada en el año 2000 también pasó por una serie de reformas en el año 2007. Diario oficial de la Unión Europea (2016).

El Tratado de Lisboa dio competencias a la Unión Europea, las organizo en 3 tipos las cuales fueron: competencia exclusiva, que era básicamente las situaciones en que el único encargado de legislar era la UE, competencias compartida que significaba que los Estados podían legislar siempre y cuando la Unión no haya actuado en el lugar correspondiente, competencia de apoyo, en este la UE se encarga de contribuir en la complementación de políticas que se encuentren debatiendo en los Estados miembros.

Cabe resaltar que es gracias al Tratado de Lisboa que se introduce una cláusula de defensa mutua, la cual garantiza el apoyo entre los miembros al ser uno de ellos objeto de agresión. Además, se cuenta con la cláusula de solidaridad, la cual se presenta en casos de terrorismo, catástrofe natural o de origen humano en los cuales los miembros de la Unión prestan asistencia con los medios disponibles, lo cual crea una suerte de seguridad europea el cual esta integrado por acciones policiales, judiciales, gestión fronteriza y protección civil los cuales van de acuerdo con los valores que apoya la Unión Europea. Cabe resaltar que en el momento mas critico de la crisis se creo una clausula de solidaridad temporal para brindar apoyo a la ubicación y reubicación de los refugiados en la cual los países que no pudieran recibir por diferentes razones se comprometían a dar el $0.002 \%$ de su pbi, además de que se analizaran los motivos por los cuales no podría y no aceptaría contribuir aceptando a los refugiados.

\subsection{Los refugiados en el Sistema Internacional}

Con el término de la Segunda Guerra Mundial en las décadas de los 50`s y 60`s, se vivió un gran periodo económico en el Viejo Continente, ya que este trajo consigo la etapa de 
reconstrucción, lo que significó una gran inversión pública, a este se le sumo el apoyo de organismos internacionales. Es debido a este suceso que se ofrecieron aumento de sueldos por la escasez en la mano de obra, además los países también recurrieron a la promoción de la inmigración selectiva para llenar el vacío que tenía la fuerza laboral europea.

En la década de los 70`s y con una Europa enrumbada en la prosperidad económica y el orden público, producto también de la creación de comunidades europeas con propósitos comunes, se asomó lo que se conocería años más tarde como la crisis del petróleo de 1973. Básicamente la crisis del petróleo fue el corte de suministros de los países árabes dueños de las grandes reservas de petróleo hacia el mundo, se vivió un alza de precios exorbitante además de una reducción en la extracción del crudo en el mundo, lo cual tuvo como resultado la desaceleración en la economía mundial.

¿Cuándo cobró importancia en el Sistema Internacional el tema del refugiado?

Al respecto Frank Krenz escribe:

Esta noción nació en Europa después de la Primera Guerra Mundial, cuando miles de personas cruzaron sus fronteras en busca de un refugio duradero. Se necesitaba entonces un estatus, un conjunto de derechos para poder mantenerse permanentemente en los países de asilo. Esto no estaba previsto en el derecho nacional e internacional porqué hasta esa época los Estados otorgaron el asilo, pero nadie se preocupó del bienestar de los asilados. Tratado de Ámsterdam (1997).

\section{- Declaración Universal de los Derechos Humanos:}

La Declaración Universal de los Derechos Humanos tuvo como propósito fortalecer los derechos de los habitantes alrededor del mundo, por lo cual la creación de los derechos universales eran imperativos en esta declaración. 
Como resultado de la cooperación de los países alrededor del mundo y la Organización de Naciones Unidas se da la DUDH que busca promover el respeto universal hacia los derechos y libertades fundamentales del hombre.

Con el breve comentario hecho párrafos arriba se resume que la DUDH es una proclamación ratificada por varios países en apoyo de la Organización de Naciones Unidas para promover el derecho y la libertad de las personas, que se reconozcan estos derechos fundamentales como universales y efectivos entre los pueblos de los Estados Miembros como de los territorios bajo su gobierno. (Unidas, 1948)

En la Declaración Universal de los Derechos Humanos de 1948 existen dos puntos que son importantes para la presente investigación, ya que forman parte de los derechos elementales de las personas y le da normativa al tema de los refugiados:

1. En caso de persecución, toda persona tiene derecho a buscar asilo, y a disfrutar de él, en cualquier país.

2. Este derecho no podrá ser invocado contra una acción judicial realmente originada por delitos comunes o por actos opuestos a los propósitos y principios de las Naciones Unidas.

\section{- La Convención de 1951 y el Protocolo de 1967}

La convención de 1951 se creó con el propósito de tener un instrumento internacional que les diera un conjunto de derechos y deberes a los refugiados para que de esta forma puedan optar por quedarse en los países a los cuales huían y pudieran acceder a una mejor calidad de vida. Además, la Convención de 1951 buscó ampliar el rango de personas que pudieran acceder a la condición de refugiado, ya que terminada las Grandes Guerras empezaron a suscitarse nuevos conflictos y la normativa no permitía acceder a ser denominado como tal por lo tanto se estipulo: 
“Que, como resultado de acontecimientos ocurridos antes del 1 de enero de 1951 y debido a fundados temores de ser perseguida...se encuentra fuera del país de su nacionalidad..." (ACNUR).

En la Convención de 1951 también se define la condición de Refugiado "sur place” el cual nos indica que una persona puede acceder a dicha condición inclusive si ya estuvo en el extranjero tiempo antes de considerarse un refugiado, no necesita necesariamente salir del país de manera irregular o por temores fundados.

El Protocolo de 1967 se creó debido a la necesidad de ampliar el rango de la condición de refugiado, a través de este protocolo se decidió eliminar las limitaciones geográficas con las que contaban los tratados anteriores además de suprimir la restricción de que los únicos que podían acceder a esta condición deberían ser los que la solicitaron antes de 1951.

Se reafirmó también que los países firmantes de la Convención y del Protocolo deben asegurarse de que los solicitantes o los ya refugiados reciban asilo y no sean devueltos a sus países de origen donde su vida se encuentra en peligro, no obstante, el ACNUR siempre esta vigilante ante cualquier irregularidad que presenten los países frente a la normativa de los refugiados.

\section{- Convenio de Dublín}

El Convenio de Dublín nace como una idea de controlar el ingreso de refugiados a territorio europeo colocando un orden a las solicitudes de asilo dándoles de esta forma ciertos parámetros para hacer estos trámites.

Inicialmente lo que se busco fue ofrecer una solución rápida en los tramites que requerían hacerse para poder solicitar el asilo, se establecieron normas claves la cuales decían de forma resumida que los solicitantes de asilo debían hacerlo en el país de entrada, lo cual causo gran 
conflicto de intereses entre los miembros del bloque, debido a que los mas afectos serian los países que cuentan con fronteras exteriores a la Unión Europea. (ACNUR Comité Español, 2018).

No obstante, este convenio ha sido modificado en dos oportunidades, esto debido a que muchas normas especificadas en el no fueron de manera muy evidente, planeadas para un tipo de crisis como esta o similar. En la actualidad podemos concluir que los problemas fronterizos se han ido agudizando con el tiempo.

A través de los años se fueron demostrando los vacíos que tenía el Convenio por eso es por lo que el término "asilos a la carta" cobro fuerza, este término hacia referencia a que los refugiados podían solicitar asilo en diferentes países, lo que aumentaba en gran porcentaje su probabilidad de obtenerla y en donde también. En las futuras modificaciones que se le realizaron al Convenio de Dublín se enfocaron en definir de forma más clara que países debían procesar las solicitudes de asilo de cada persona, la idea consistió en asociar de forma tangible al refugiado con uno de los países miembros en los que su adherencia a la sociedad fuera más fácil, además se creó la norma que especificaba que la solicitud se debía presentar solamente ante un país. (Vial, 2017).

\section{- Redes de Tráfico de Refugiados}

Con toda la crisis que se vive en la Unión Europea con la llegada de inmigrantes también es importante analizar la travesía que estos toman para poder acceder a territorio europeo, en el siguiente capitulo se detallaran las diferentes rutas que los refugiados deciden tomar para enrumbarse en este peligroso recorrido.

Cabe resaltar que gracias a la gran afluencia de personas tratando de acceder a territorio europeo por el mar Mediterráneo se crearon mafias dedicadas a este negocio las cuales cobran una cierta cantidad de dinero que oscila entre los 1000 y 2000 euros. No obstante, estas mafias camuflan 
a los refugiados dentro de embarcaciones la cuales en muchas ocasiones no reúnen ni un mínimo de seguridad es decir exponen la vida de las personas y cobran por ello. Es necesario resaltar que el ingreso que han podido llegar a obtener estas mafias rondan los 7000 millones de euros. Es también de conocimiento público que estas mafias se dedican a la trata de personas y que ellos tienen puntos de reclutamientos en los que sus organizaciones se encuentran establecidas. En síntesis, gracias a los conflictos que se llevan a cabo en países como Siria los habitantes desean huir y refugiarse en otros países, muchas veces eligen a Europa como dicho destino, tal ha sido la repercusión que han tenido estas redes de tráfico de refugiados que ha sido catalogada como la "Transnacional del tráfico de personas" por algunos medios periodísticos. (ONU, 2018).

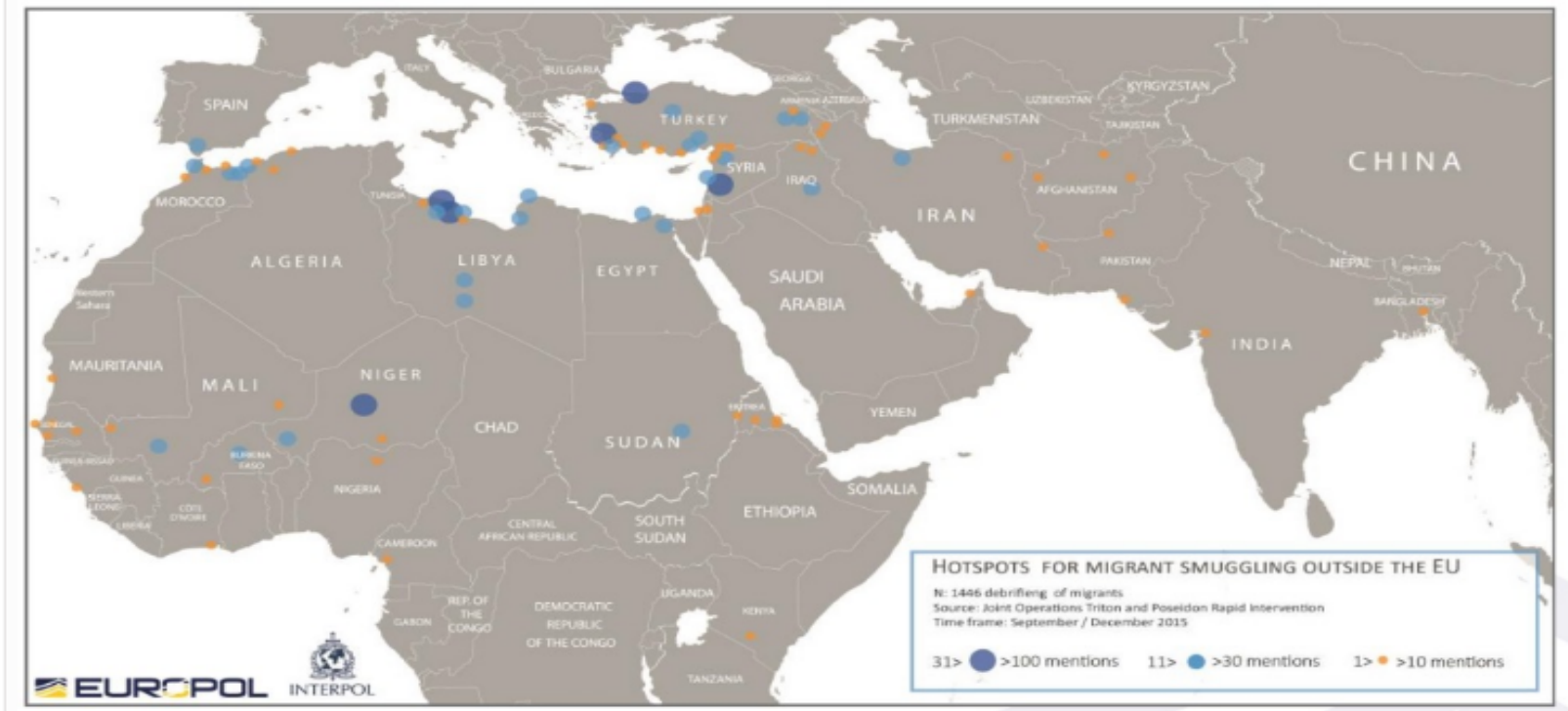

Puntos de reclutamiento de migrantes para el tráfico de personas fuera de la UE

Figura1: Puntos de reclutamiento de migrantes para el trafico de personas fuera de la UE Fuente: Europol, Interpol. 


\subsection{Crisis de los Refugiados impacto en la Unión Europea}

"Vivir como refugiado es como estar atrapado en arenas movedizas - cada vez que te mueves, te hundes aún más", fueron las declaraciones de un padre de familia ha encargados del ACNUR. Lo dicho por el entrevistado refleja de manera clara el suplicio en el que se encuentras millones de personas que han salido de su país en busca de refugio.

Según Vasile (2015):

The current situation has to be seen in a broader context of violent conflict and destabilization in other parts of the World. It is a crisis of unprecedented magnitude that largely originates from conflicts and persecutions in Europe`s wider neighborhood. [La situación actual debe verse en un contexto más amplio de conflicto violento y desestabilización en otras partes del mundo. Es una crisis de una magnitud sin precedentes que en gran parte se origina a partir de conflictos y persecuciones en el vecindario más amplio de Europa].

La crisis de los refugiados ha repercutido enormemente en los países miembros de la Unión Europea, pero podemos encontrar países que son los que se han visto mas perjudicados por la llegada de estas masas debido a que son países de entrada, los cuales son: España, Italia, Grecia, Malta y Hungría.

Además, podemos encontrar la denominación de las principales vías de acceso al Continente Europeo, en los que destacan muchos países africanos, los cuales han servido como lugares de tránsito para poder adentrarse en las peligrosas rutas del mediterráneo. 


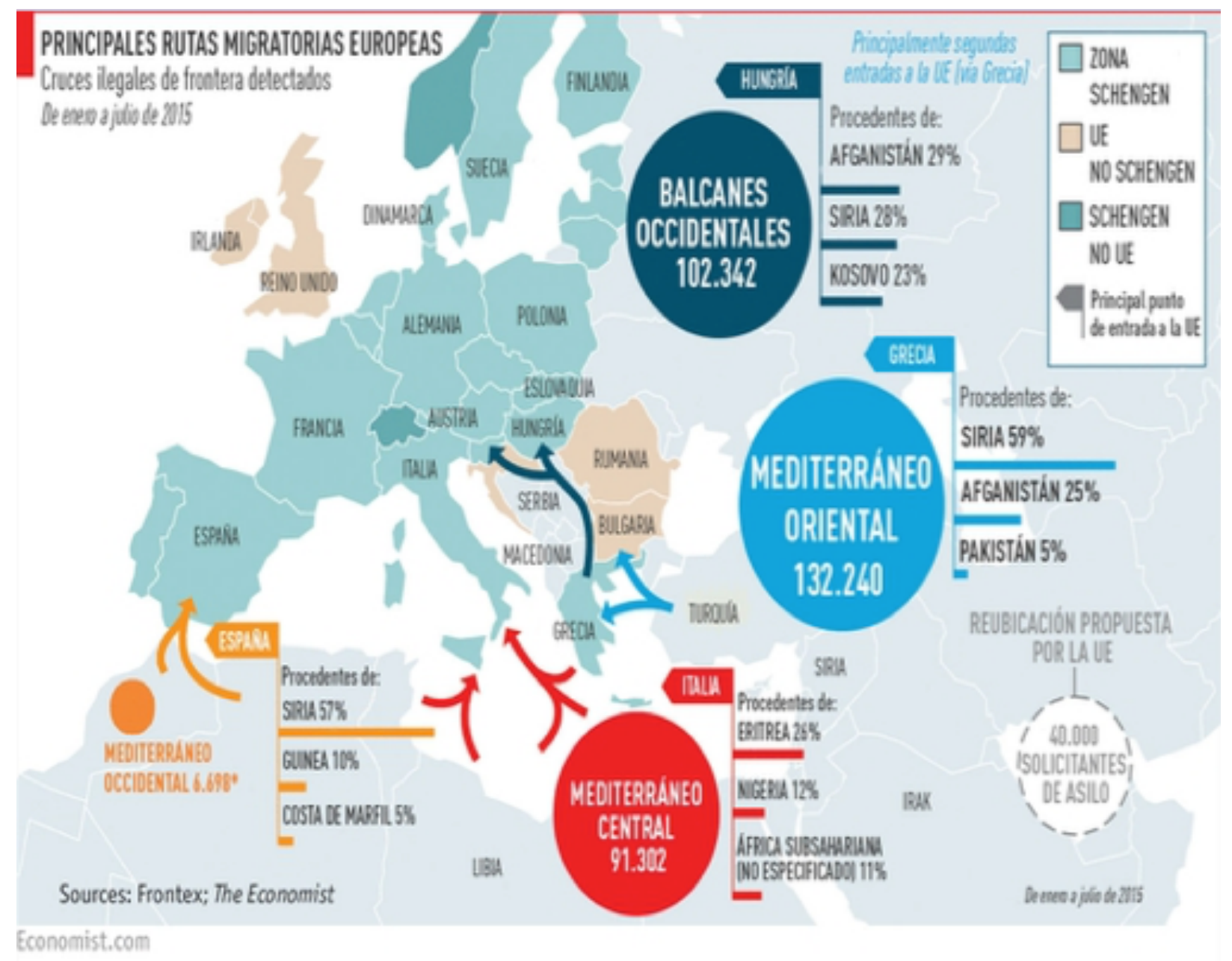

Figura 2: Principales rutas migratorias europeas. Fuente: (INFOBAE)

Además, podemos observar que rutas utilizan los habitantes de cada país para acceder a territorio de la Unión Europea. Como se puede observar en el siguiente mapa los habitantes de los países africanos toman como su principal ruta de acceso la del Mediterráneo Central, el cual tiene como su principal salida países como Túnez, Marruecos o Libia.

En el foco del tema de la investigación la ruta que más ha traído controversias al continente europeo es la del Mediterráneo Oriental, debido a las grandes olas de refugiados que han optado en esta como su principal salida, los habitantes de países como Siria, Irak, Irán, Pakistán optan por tomar esta ruta como su principal vía de acceso al Viejo Continente.

Volviendo al tema central de la investigación y del punto en particular ¿Por qué se resalta este tipo de información? Por qué en la ruta demarcada en el cuadro el principal país de tránsito era 
Turquía, al cual utilizaban como puerto para adentrarse al mediterráneo y por consiguiente llegar a Europa.

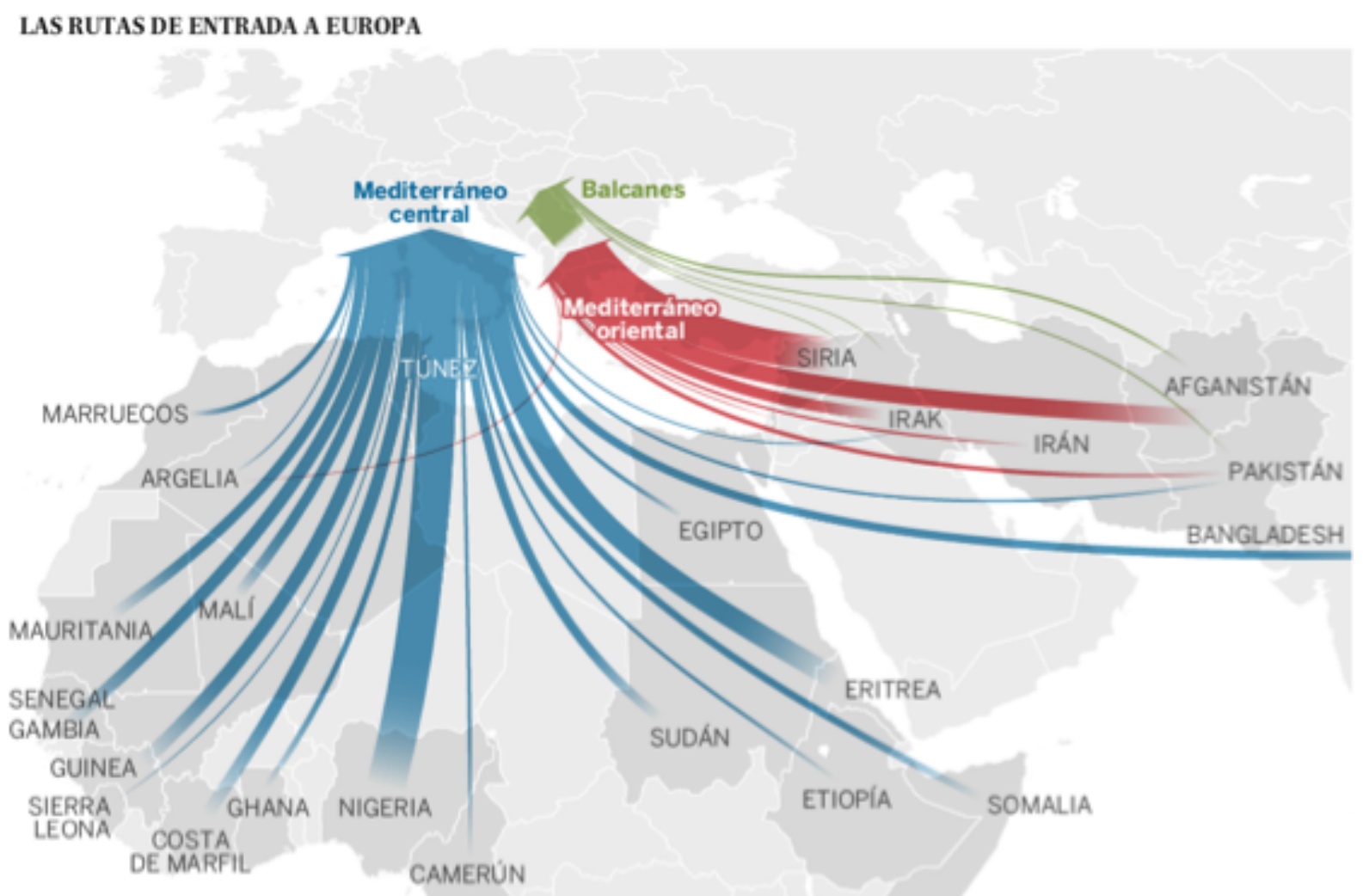

Figura 3: Las rutas de entrada a Europa. Fuente: (País, 2017)

"No hay ruta más mortal para los migrantes que la del Mediterráneo" (Febbro, 2015). La crisis de los refugiados ha sido y continúa siendo uno de los principales retos de la Unión Europea como organismo, ya que cuestiona su capacidad de hacer frente a ella de forma apropiada, toda vez que las personas que llegan a sus costas puedan no solo acceder a establecerse en su territorio si no también el recibir servicios básicos para no vivir en niveles aún más bajos que el de la pobreza.

La magnitud de la crisis ha convertido a esta en una de las más grandes de la historia europea, los hechos han sido desgarradores y los resultados hasta el momento poco prometedores. 
La crisis de los refugiados que se da lugar en la Unión Europea ha tenido como causas las grandes guerras en el medio oriente un claro ejemplo es la guerra en Siria la cual luego de 8 años aun no ha llegado a su fin. Desde el inicio de la guerra en Siria hasta el momento se encuentran alrededor de 370,000 muertos de los cuales 112,000 han sido civiles (Arab News, 2019), las cifras son alarmantes y explican el contexto bajo el cual las personas huyen de sus hogares llegando así a Europa en busca de protección.

Según el Observatorio Sirio para los Derechos Humanos, de los muertos hasta el momento 21,000 han sido menores de edad y alrededor de 13,000 han sido mujeres. (rights, 2019) En la actualidad se estima según la Oficina de Coordinación Humanitaria de la ONU que:

6,5 millones de sirios se han convertido en refugiados

$>6,1$ millones se han desplazado dentro del país

$>13,1$ millones de personas necesitan protección

670.000 personas han retornado al país. (Gamba, 2018)

Las cifras que se encuentras en las Agencias encargadas de medir la magnitud del conflicto resultan ser escalofriantes debido al gran número de muertes que ha provocado, pero ¿Es esto importante para entender el núcleo de la investigación? Es precisamente para eso que se hace énfasis en los resultados de la guerra que se está llevando a cabo en Siria desde 2011, ya que la gran mayoría de los refugiados que llegan a Europa por las diferentes rutas, como la ya mencionada del "Mediterráneo", provienen de este sector.

Bajo esta premisa la crisis que se vive en la Unión Europea se origina debido al gran conflicto que se vive en Siria y en diferentes territorios que como este han causado una gran desestabilización en la política, economía y sociedad europea.

Para poder entender las consecuencias que han tenido en las políticas internas de los países como la creación de partidos de extrema derecha con tendencias xenófobas, decisiones de los mandatarios en contra de los refugiados para el aumento en la aprobación por parte de los 
votantes entre otros debemos analizar las cifras que ha traído consigo el conflicto como se ha visto reflejado en el ingreso de refugiados, de que países vienen y cuáles son los principales países de destino.

\section{Asylum applications (non-EU) in the EU-28 Member States, 2006-2017}

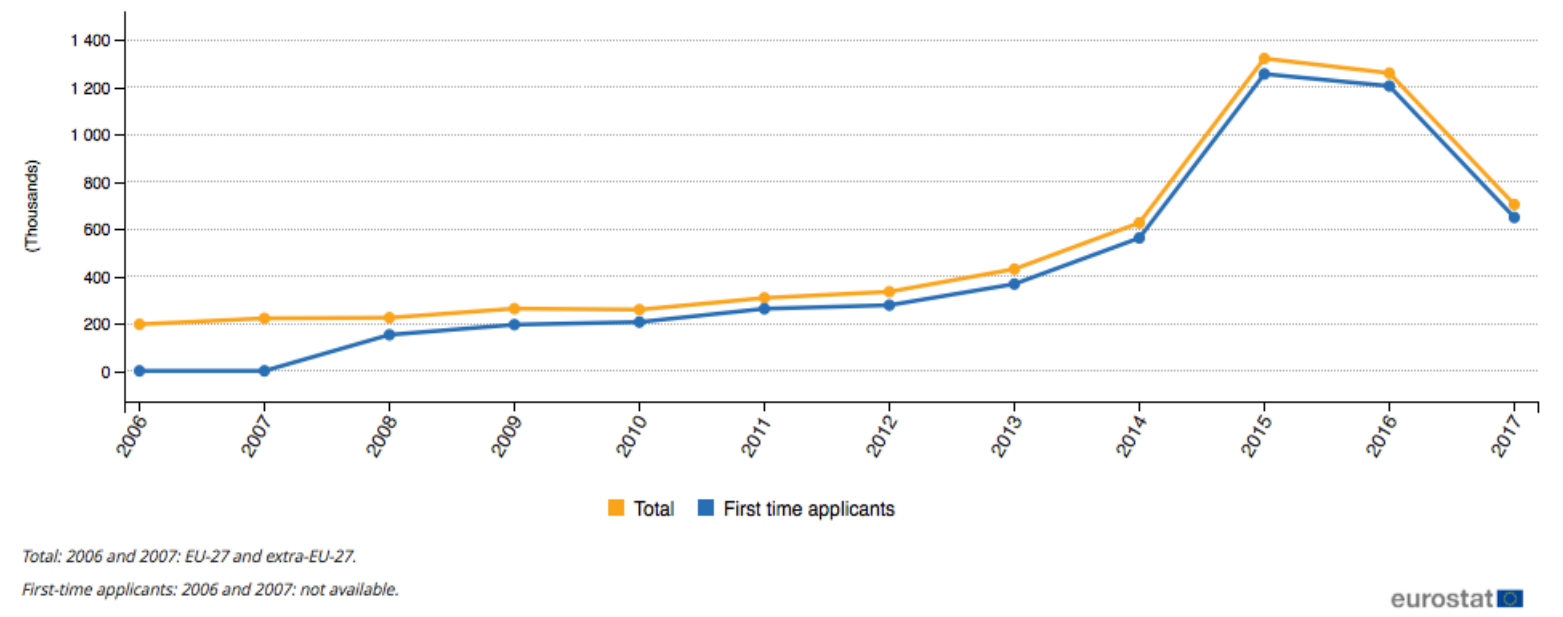

Figura 4: Aplicaciones de asilo. Fuente: Número de solicitantes de asilo (Asilo, 2019)

Los índices de ingreso de solicitudes de asilo de los principales países de la Unión Europea ya sean los países de llegada o países de acceso directo (fronteras exteriores), han ido evolucionando durante los años. El crecimiento se dio a partir del año 2014 y los picos más altos fueron durante el 2015 y 2016, no obstante, las medidas tomadas por la Unión Europea ayudaron a que esta tendencia que inicio en el año 2012 de forma notoria culminara. 
La variación exponencial de las solicitudes de asilo en los países europeos es una prueba más de la constante evolución tanto del conflicto en los estados vecinos, como de las ineficientes decisiones que se vienen ejecutando por el bloque.

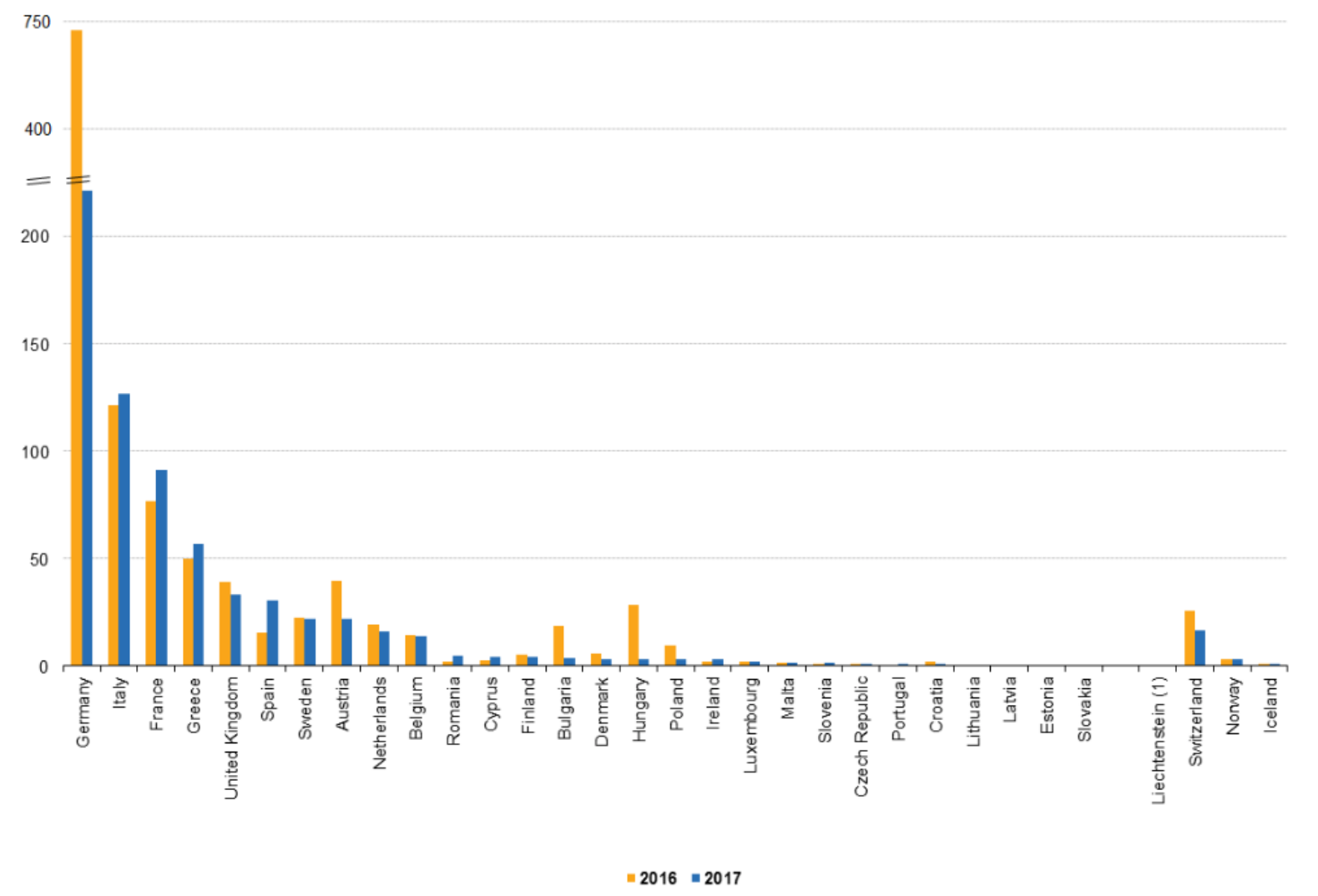

Figura 5: Fuente: Número de solicitantes de asilo (Asilo, 2019)

Para poder entender el alcance que ha tenido esta crisis y como se explica que haya una reducción en solicitudes pero que en algunos países en particular haya aumentado tenemos que conocer el caso de Alemania el cual fue el principal receptor de solicitudes con un pico de alrededor de 745000 solicitudes en 2016.

Política que cambió en el año siguiente, esto debido a la poca aprobación de Angela Merkel después de los atentados terroristas de 2016 en la ciudad de Berlín, el cual fue uno de los principales motivos que hizo que la aceptación de solicitudes de refugiados en el país Teutón disminuyera. El rechazo por parte de la población fue gracias al aumento en la sensación de inseguridad interna provocada por el gran aumento de población musulmana (el atentado fue 
atribuido a ISIS) por lo que la población asociaba directamente a todos los ciudadanos musulmanes, no obstante, a pesar de la gran caída en las solicitudes de asilo Alemania sigue siendo el país que acoge a la mayoría de los refugiados en Europa.

Sin embargo, en el cuadro dos también podemos observar que países son los que recepcionan más solicitudes de asilo, entre los cuatro primeros países cabe resaltar la presencia de Italia y Grecia, ya que como se explicara en el siguiente capítulo son de los principales países a favor de reformar el Convenio de Dublín.

Por otro lado, al ya conocer el flujo de solicitudes debemos también investigar de que países proviene la gran mayoría de estas. Como ya se mencionó en el primer punto de este capítulo, la gran mayoría proviene de Siria, además cierta parte del flujo restante proviene también de países como Irak, Irán y Afganistán. ¿Por qué es importante saber de dónde provienen?, es necesario saber de dónde proviene la mayoría de la migración ya que esto nos ayuda a saber el impacto que tendrá en la sociedad debido a que la crisis de los refugiados ha traído consigo un flujo importante de habitantes con diferentes culturas a la europea. Esto ha provocado el crecimiento de movimientos políticos extremistas gracias a la propagación de pensamientos populistas.

El rechazo de las personas por el intento de imponer culturas distintas al del país receptor por parte de ciertos grupos de inmigrantes y también para facilitar la integración de estos mismos a través de programas en los cuales se les enseña y adecua a las costumbres europeas.

En la imagen número tres se puede apreciar cuales son los países "surtidores" de refugiados a la Unión Europea, en el cual podemos observar que existen algunos que sobresalen dentro de los demás, debido a los incesantes y devastadores conflictos o a la inestabilidad de los gobiernos de estos actores el flujo migratorio aumento en forma excesiva.

Observando la imagen también podemos afirmar que las políticas comunes, que se han intentado implantar o las que ya existían antes de que se desarrolle esta crisis, han fallado y es 
que encontramos que países como Italia y Grecia cuentan con mas solicitudes esto debido a que son países de entrada a territorio de la Unión Europea pero que finalmente estos refugiados apuntan a terminar en Alemania u otros países.

En el siguiente cuadro se aprecia de donde proviene la mayoría de los refugiados, con esta información se puede inducir que el impacto social es muy grande, ya que tanto la cultura europea como la musulmana tienen características muy distintas la una de la otra, por lo que para contar con una política común exitosa se debe albergar todos los aspectos que estos conlleven y que se encuentre un punto de similitud entre ambas.

Cabe resaltar que a pesar de que se ha reducido en mas de la mitad los refugiados provenientes de Siria este continúa siendo el país del que salen más refugiados hacia Europa.

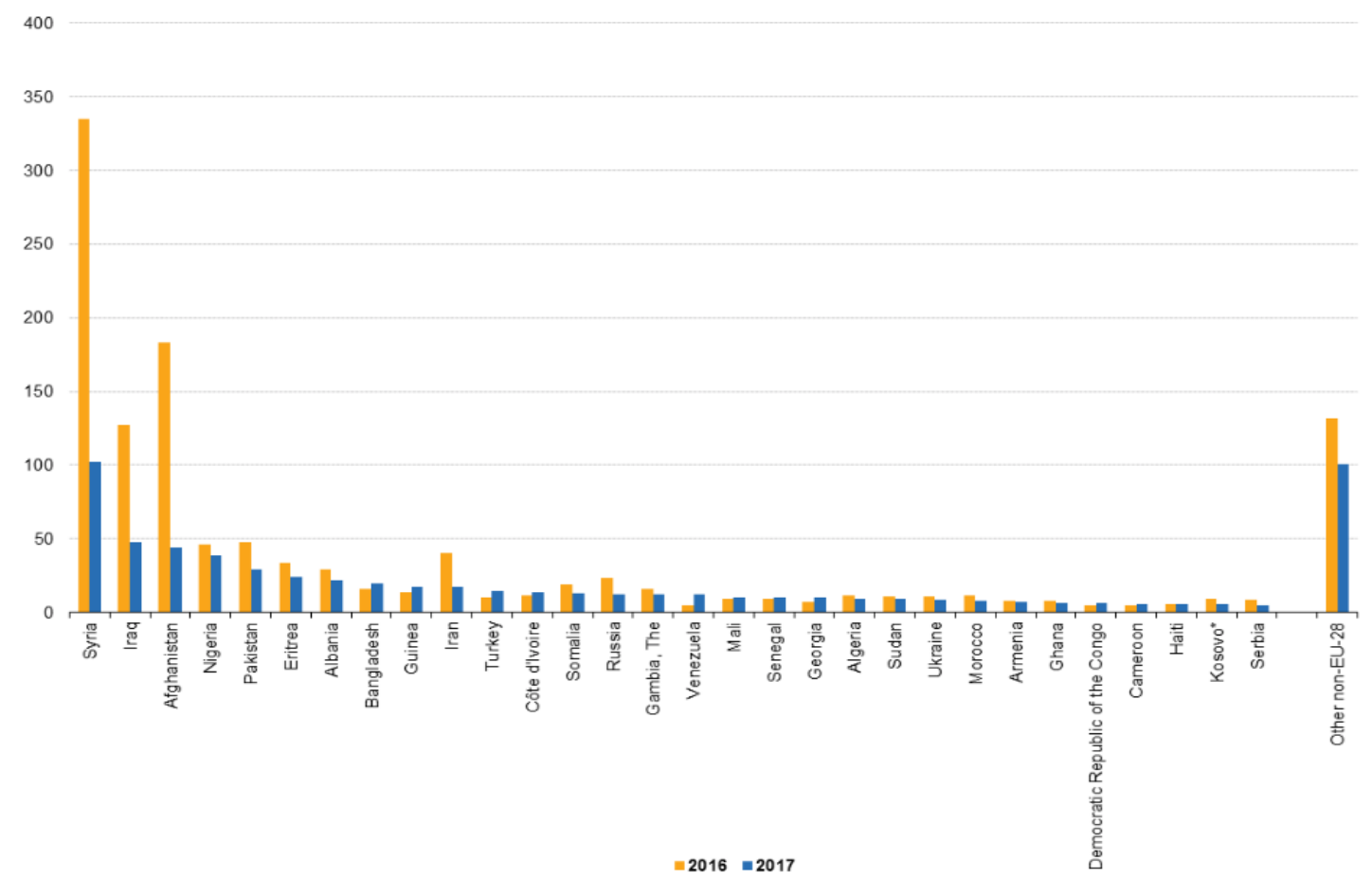

Figura 6: Fuente: Número de solicitantes de asilo (Asilo, 2019)

Tal y como se pudo haber observado en las estadísticas anteriores, la población musulmana en Europa es cada vez más grande, en consecuencia, la cultura musulmana se ve mas inmersa en el día a día de los locales. 
La cifra actual de mezquitas es similar a la existente en iglesias católicas, se calcula que aproximadamente por cada 1890 musulmanes que residen en Europa existe una mezquita, dato alarmante debido a que refleja la creciente presencia de musulmanes en el continente.

Recapitulando, tras las cifras que nos ofrece Eurostat la gran mayoría de los inmigrantes que han llegado a Europa son musulmanes. Los países que podrían ser llamados fronterizos, son los más afectados, el revuelo en el aspecto social se ha podido presenciar de forma clara. Es necesario hacer hincapié en este tema ya que ambas culturas son en su mayoría diferentes, por lo que el choque que se vive en el día a día ha creado un sentimiento de rechazo por parte de los locales hacia los refugiados e inclusive hacia todo tipo de inmigración. (De Miguel, 2009) 


\section{CAPÍTULO V: RESULTADO DE LA INVESTIGACIÓN}

\section{Resultados de la Investigación}

La investigación realizada abarcó desde noticias de diarios europeos, páginas oficiales de organismos relacionados a la crisis de los refugiados, estatutos de la Unión Europea hasta entrevistas a representantes oficiales de actores que se han visto envueltos de forma directa o indirecta en esta problemática.

Las decisiones que han sido tomadas hasta el momento para hacerle frente a la crisis no han sido capaces de erradicar este problema de raíz y es que con soluciones temporales lo único que se logrará será el deterioro de las relaciones entre países que en cierta parte se ven más beneficiados que otros.

Esta continua toma de decisiones por parte de la Unión Europea ha sido catalogada por muchos órganos internacionales, como inhumana e incomprensible según las bases del bloque, por lo que el término "Europa Fortaleza", un término plenamente empleado a través de la historia como critica a las políticas mal planteadas que han gozado de poca aceptación tanto del público general como de la prensa europea y mundial, ha empezado a utilizarse haciendo referencia en este caso en particular a las diferentes políticas y acciones migratorias llevadas a cabo por el órgano en mención.

Es prudente mencionar algunas implicancias que ha tenido hasta el momento algunas decisiones tomadas de forma singular en algunos estados y también del bloque en conjunto, las implicancias pueden formar parte de la esfera política, social o económica. 


\subsection{Factores políticos y sociales}

En el siguiente punto analizaremos los factores políticos y sociales que han dificultado en pequeña o gran magnitud la adopción de una política común por parte del bloque europeo frente a la crisis de los refugiados.

\section{- Crecimiento de partidos de extrema derecha}

La crisis de los refugiados ha tenido y sigue teniendo implicancia en temas sensibles dentro de la Unión Europea. En este caso en particular se ha visto reflejado en la aparición de partidos de extrema derecha que sientan las bases de su movimiento en reforzar el conservadurismo y culpar a la descontrolada inmigración de las dificultades que presenta el bloque.

El rechazo a los refugiados y en general a todo tipo de inmigración no es la única estrategia que suelen utilizar estos partidos, sino que también fusionan ideas de izquierda que se ven reflejadas en una serie de propuestas como la de nacionalizar el sector privado, entre otros. Se podría interpretar a este movimiento entonces como una suerte de derecha populista que respalda la soberanía estatal, lo cual produce una lucha en contra de lo que propone la Unión Europea, que es unir a los países y crear una base en la que todos los países cuenten con instituciones y normas comunes para promover la unificación del bloque.

En la imagen se observa el alcance que tienen y podríamos suponer el que tendrían en unos años los partidos de extrema derecha. 


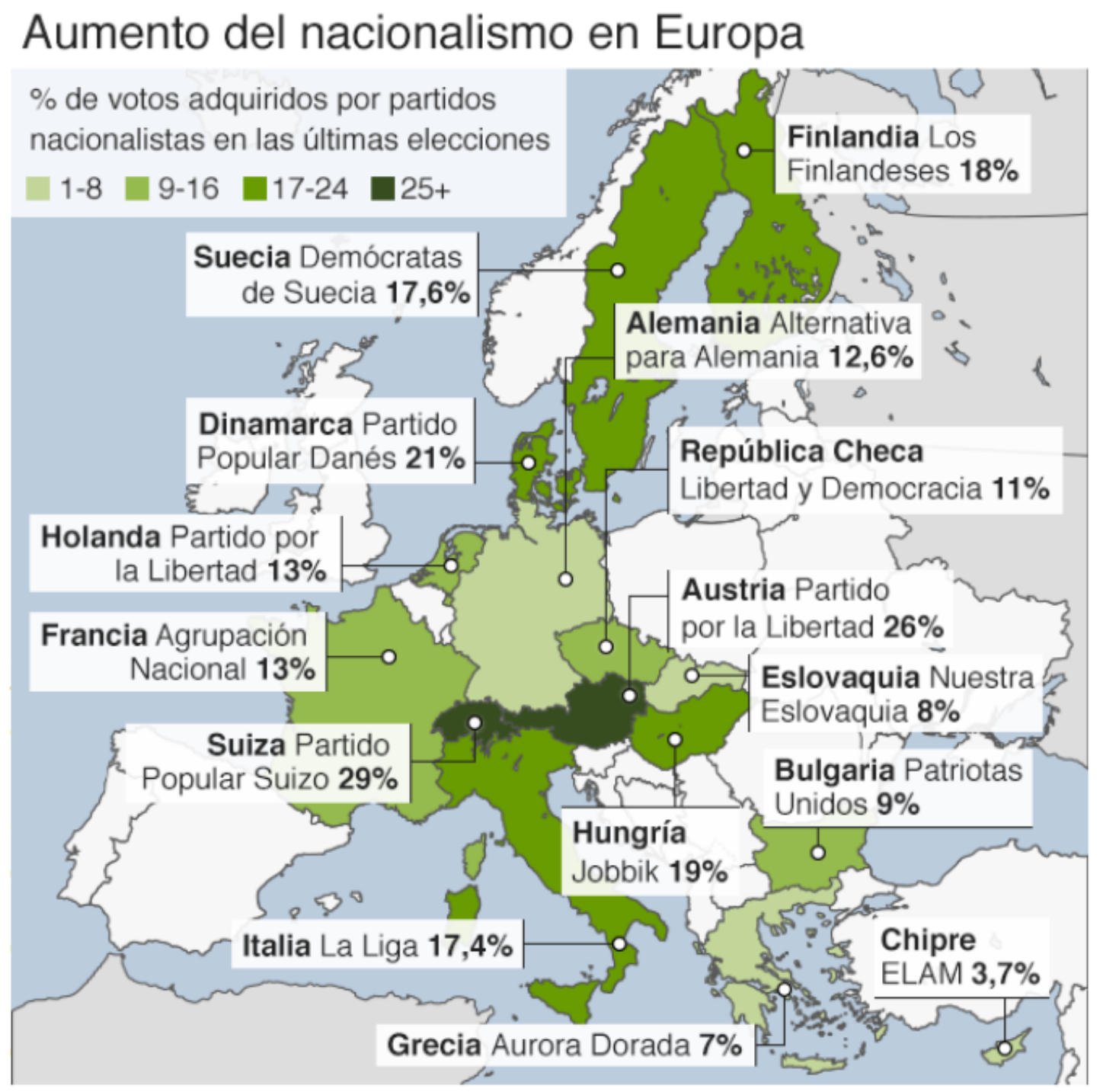

Figura 7: Aumento del nacionalismo en Europa. Fuente: Orgaz (2018)

Entonces ¿Por qué corre riesgo la Unión Europea y por qué no se llega a una solución conjunta para todos los miembros? Esto se debe a las discrepancias existentes entre algunos gobiernos que no respaldan y otros que si las ideas antiinmigrantes. Esto ha tenido como consecuencia la aparición de partidos políticos en los últimos años, en su mayoría de extrema derecha beneficiándose de una suerte de oportunidad en lo poco informada que se encuentra la población europea. 
Como ya se mencionó, estos partidos y sus corrientes ideológicas respaldan ideas que van en contra de la "integración europea", las cuales afectan en mayor medida las bases de la Unión Europea y que por consecuencia dificultan la existencia de una política común entre los países miembros.

\section{- Proyecto de reforma Convenio de Dublín}

Las reformas que se le plantean hacer al Convenio de Dublín son precisamente para evitar el desbalance y que exista una distribución más justa de los solicitantes que arriban a tierras europeas, por lo que el nuevo sistema contribuye a esta causa y además ayudara a tener una respuesta inmediata sobre la colocación de los refugiados en otros países, de esta forma se evitarían los "asilos a la carta".

La creación del sistema ayudará a reconocer según porcentajes que país está recibiendo más solicitudes (150\% será la cantidad) a comparación de otros países, tras lo cual se les reubicará en países miembros de la UE, de ser aprobada las solicitudes, hasta llegar a un equilibrio pertinente. Se agrega además la "contribución de solidaridad” esta imponía que los países que no quieran someterse a la repartición de los refugiados deberían pagar 250,000 euros por cada solicitante que estos mismos rechazaran en su territorio.

Esto traería consigo que el sistema bajo el cual se ha actuado estos años mejore y sea eficiente, esto gracias a que reducirá el tiempo en cuanto a la recepción de las respuestas de asilo, un plazo mas breve para la transmisión de solicitudes de traslado a otros países y además se eliminarán vacíos que existían en las obligaciones legales de los mismos.

Las reformas al Convenido de Dublín son de suma importancia para este conflicto y para conflictos similares que se puedan dar en un futuro ya que hacen parte de la normativa legal de recepción por parte de extranjeros a territorio europeo. 


\section{- Proyecto de reforma Acuerdo Schengen}

El Acuerdo Schengen tuvo como función principal unir en un espacio libre a los países europeos, para de esta forma poder fomentar el trabajo, el turismo y que la interacción cultural y social se ampliara a través del tiempo, con las barreras fronterizas abolidas empezó el traslado de europeos entre los países y se logró en parte lo buscado por el acuerdo. No obstante, bajo las circunstancias actuales es decir frente a la crisis de los refugiados que se vive en Europa se debate la modificación del acuerdo y la implementación de nuevos sistemas para optimizar el funcionamiento de este, brindar más seguridad y reducir los requisitos al plantear el restablecimiento del control de las fronteras.

El hecho de pensar en la eliminación del espacio Schengen por parte de algunos países es una de las más grandes muestras de que la integración europea se encuentra en riesgo, esto debido a que este acuerdo fue uno de los grandes pilares que impulso la unificación del Viejo Continente y que en números generales fue satisfactorio para la sociedad europea.

Se discute la reintegración total del control de fronteras en el continente, lo cual afectaría en gran parte las bases en las que se formó la integración europea, ya que esta fue impulsada en gran parte por el libre tránsito que facilitaba el acuerdo de Schengen.

Desde el inicio de la crisis se ha incrementado de forma considerable el restablecimiento del control de las fronteras interiores de los países pertenecientes al Acuerdo, debido a que este flujo masivo de entradas ponía en riesgo la seguridad interna de los estados miembros. 
Tabla 1: Controles internos dentro del espacio Schengen (2006-2017)

CONTROLES INTERNOS DENTRO DEL ESPACIO SCHENGEN (2006-2017)

\begin{tabular}{|c|c|c|c|}
\hline Afio & País que lo realiza & Núm. & Razones \\
\hline \multirow{2}{*}{2006} & Francia & 1 & Evento \\
\hline & Fintandia & 2 & Evento político \\
\hline \multirow{3}{*}{2007} & Francia & 1 & Evento político \\
\hline & Alemania & 1 & Evento político \\
\hline & Islandia & 1 & Evento \\
\hline \multirow{3}{*}{2008} & Austria & 1 & Evento deportivo [Eurocopa 2008] \\
\hline & Francia & 1 & Movilización social \\
\hline & Finlandia & 1 & Evento político \\
\hline \multirow{8}{*}{2009} & Islandia & 1 & Evento \\
\hline & Alemania & 1 & Evento político \\
\hline & \multirow{2}{*}{ Francia } & \multirow{2}{*}{3} & 2 por Evento político \\
\hline & & & Movilización social \\
\hline & Italia & 1 & Evento político \\
\hline & Esparia & 1 & Movilización social \\
\hline & Noruega & 1 & Evento \\
\hline & Dinamarca & 1 & Evento político \\
\hline \multirow{5}{*}{2010} & Malta & 1 & Evento \\
\hline & Estonia & 1 & Evento político \\
\hline & Francia & 1 & Evento político \\
\hline & Letonia & 1 & Evento político \\
\hline & Portugal & 1 & Evento político \\
\hline \multirow{4}{*}{2011} & Austria & 1 & Evento político \\
\hline & Noruega & 1 & Ataque terrorista \\
\hline & Suecia & 1 & Ataque terrorista \\
\hline & Francia & 1 & Evento político \\
\hline
\end{tabular}


DIFICULTADES DE UNA POLÍTICA COMUN EN EUROPA ANTE LA CRISIS DE LOS REFUGIADOS

\begin{tabular}{|c|c|c|c|}
\hline \multirow{3}{*}{2012} & España & 1 & Evento político \\
\hline & Polonia & 1 & Evento deportivo [Eurocopa 2012] \\
\hline & Noruega & 1 & Evento \\
\hline 2013 & Polonia & 1 & Evento político \\
\hline \multirow{4}{*}{2014} & Países Bajos & 1 & Evento \\
\hline & Bélgica & 1 & Evento político \\
\hline & Noruega & 1 & Amenaza terrorista \\
\hline & Estonia & 1 & Evento político \\
\hline \multirow{10}{*}{2015} & \multirow{2}{*}{ Alemania } & \multirow{2}{*}{6} & Evento político \\
\hline & & & 5 por movimientos migratorios \\
\hline & Austria & 5 & Movimientos migratorios \\
\hline & Eslovenia & 2 & Movimientos migratorios \\
\hline & Hungría & 1 & Movimientos migratorios \\
\hline & Malta & 1 & Evento político/amenaza terrorista/Lucha contra el tráfico de personas \\
\hline & Suecia & 1 & Movimientos migratorios \\
\hline & \multirow{2}{*}{ Francia } & \multirow{2}{*}{2} & Evento político \\
\hline & & & Estado de emergencia [Ataques de París 13/10/2015] \\
\hline & Noruega & 1 & Movimientos migratorios \\
\hline \multirow{18}{*}{2016} & \multirow{4}{*}{ Dinamarca } & \multirow{4}{*}{4} & Movimientos migratorios \\
\hline & & & Movimientos migratorios \\
\hline & & & $\begin{array}{l}\text { Recomendación del Consejo de } 12 \text { de mayo de } 2016 \text { bajo el artículo } 29 \text { (1). } \\
\text { Criterio [a] Movimientos migratorios }\end{array}$ \\
\hline & & & $\begin{array}{l}\text { Recomendación del Consejo el } 11 \text { de noviembre de } 2016 \text { (2). } \\
\text { Criterio [a] Movimientos migratorios }\end{array}$ \\
\hline & \multirow{3}{*}{ Suecia } & \multirow{3}{*}{3} & Movimiento migratorios \\
\hline & & & $\begin{array}{l}\text { Recomendación del Consejo el } 7 \text { de febrero de } 2017 \text { (3). } \\
\text { Criterio [b] Movimientos migratorios }\end{array}$ \\
\hline & & & $\begin{array}{l}\text { Recomendación del Consejo el } 11 \text { de noviembre de } 2016 \text { (2). } \\
\text { Criterio [a] Movimientos migratorios }\end{array}$ \\
\hline & \multirow{3}{*}{ Noruega } & \multirow{3}{*}{3} & Movimientos migratorios \\
\hline & & & $\begin{array}{l}\text { Recomendación del Consejo el } 12 \text { de mayo de } 2016 \text { bajo el artículo } 29 \text { (1). } \\
\text { Criterio [a] Movimientos migratorios }\end{array}$ \\
\hline & & & $\begin{array}{l}\text { Recomendación del Consejo del } 11 \text { de noviembre de } 2016 \text { (2). } \\
\text { Criterio [a] Movimientos migratorios }\end{array}$ \\
\hline & Bélgica & 1 & Movimientos migratorios \\
\hline & \multirow{2}{*}{ Francia } & \multirow[b]{2}{*}{2} & Evento deportivo [Tour de Francia] \\
\hline & & & $\begin{array}{l}\text { Estado de emergencia [Ataques de Niza, } 14 / 7 / 2016 \text { ] Estado de emergencia } \\
\text { [Atques de Niza, } 14 / 7 / 2016]\end{array}$ \\
\hline & \multirow{2}{*}{ Alemania } & \multirow{2}{*}{2} & $\begin{array}{l}\text { Recomendación del Consejo el } 12 \text { de mayo de } 2016 \text { bajo el articulo } 29 \text { (1). } \\
\text { Criterio [a] Movimientos migratorios }\end{array}$ \\
\hline & & & $\begin{array}{l}\text { Recomendación del Consejo el } 11 \text { de noviembre de } 2016 \text { (2). } \\
\text { Criterio [a] Movimientos migratorios }\end{array}$ \\
\hline & \multirow{2}{*}{ Austria } & \multirow{2}{*}{2} & $\begin{array}{l}\text { Recomendación del Consejo el } 12 \text { de mayo de } 2016 \text { bajo el articulo } 29 \text { (1). } \\
\text { Criterio [a] Movimientos migratorios }\end{array}$ \\
\hline & & & $\begin{array}{l}\text { Recomendación del Consejo el } 11 \text { de noviembre de } 2016 \text { (2). } \\
\text { Criterio [a] Movimientos migratorios }\end{array}$ \\
\hline & Polonia & 1 & Eventos políticos \\
\hline
\end{tabular}


DIFICULTADES DE UNA POLÍTICA COMUN EN EUROPA ANTE LA CRISIS DE LOS REFUGIADOS

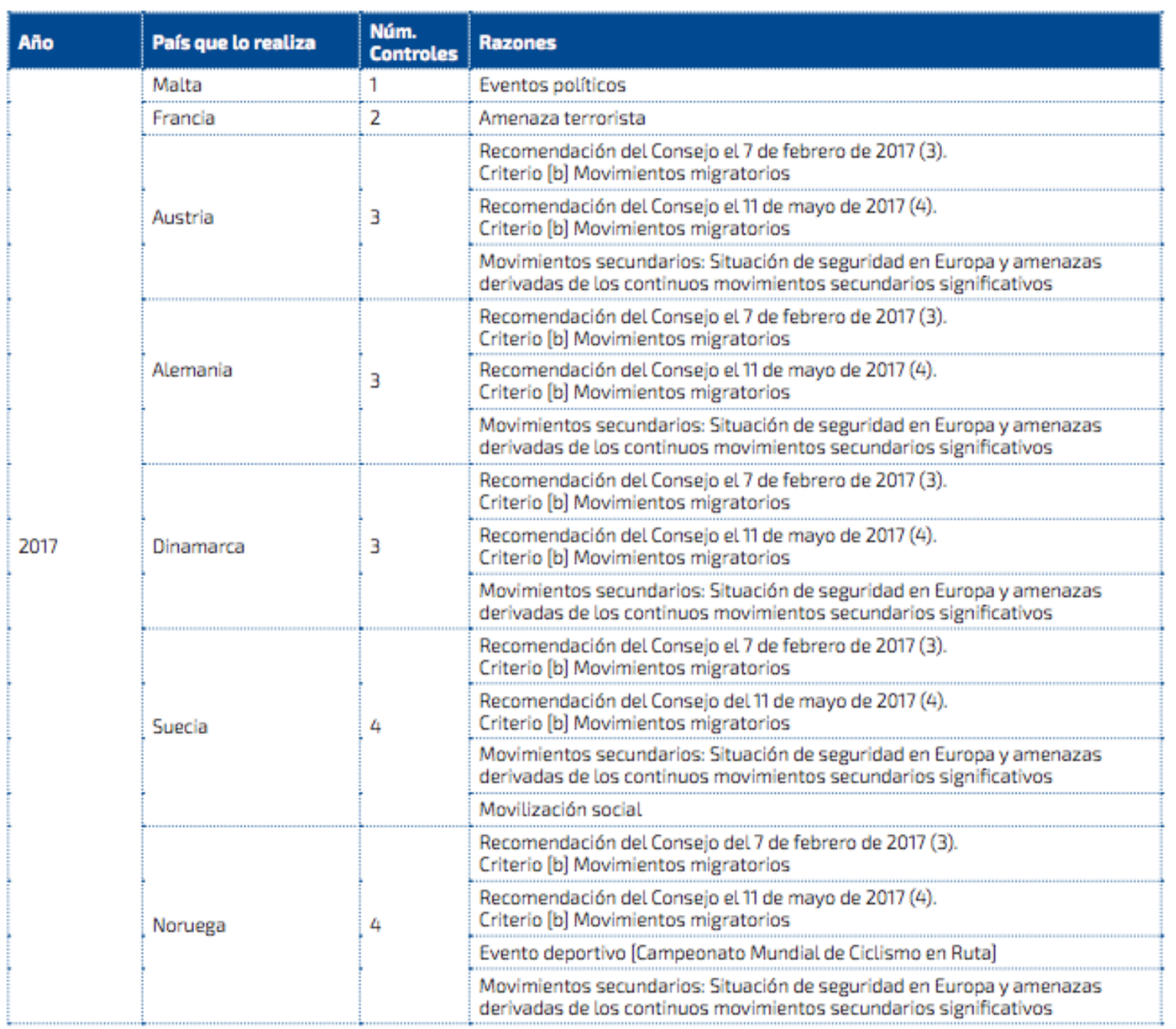

Fuente: Elaboración propia a partir de fuentes del Parlamento Europeo (Parlamento Europeo, 2016)

Notas sobre los criterios:

Evento: eventos 0 acontecimientos sociales a gran escala

Evento politico: reuniones o cimeras a nivel internacional como una cimera de cambio climático o de la OTAN.

"Movimientos secundarios significativos": movimientos migratorios dentro del espacio Schengen. Según definición del Consejo Europeo "Movimiento de refugiados o solicitantes de asilo desde los países en los que ya gozan o pudieran gozar de protección, con el objeto de solicitar asilo o reasentamiento permanente en otro país, sin el consentimiento previo de las autoridades nacionales de este último, sin contar con un visado de entrada o con suficiente documentación de viaje" Fuente: http://late.europa.eu/FindTermsByLilld.do?uldd=911515Etangld=es

Movilización social: manifestación que implica un nivel alto de desplazamiento de personas por la vía pública.

Movimientos migratorios: movimientos de personas migradas en las fronteras exteriores o interiores del espacio Schengen

Notas sobre los criterios con recomendación del Consejo Europeo:

[a] "graves problemas para garantizar un control eficiente de la frontera exterior, de conformidad con el acervo de Schengen, y la acogida y el tratamiento de los migrantes que llegan [....

[b] "(...) prorrogar la realización de controles temporales en las fronteras interiores en circunstancias excepcionales que pongan en peligro el funcionamiento global del espacio Schengen [_]". Las "circunstancias excepcionales", se pueden describir como "(...] la seria amenaza para el orden público y la seguridad interior que se cierne sobre estos Estados por la combinación de deficiencias en el control de las fronteras exteriores en Grecia y por los movimientos secundarios de migrantes irregulares que entran a través de Grecia con la posible intención de trasladarse a otros Estados Schengen [...]"

Fuente: (Ruiz \& Brunet, 2018) 
Con las variables descritas en el cuadro anterior podemos inferir que el funcionamiento de Schengen en la situación actual de la Unión Europea debe variar y es que acuerdos de integración regional como este siempre deben estar en constante adaptación a los contratiempos que se presenten, cabe resaltar que a pesar de que el restablecimiento en el control de las fronteras es una herramienta valida, por parte de los estados miembros del Acuerdo de Schengen, el continuo uso de la misma hace que se pierda la esencia del mismo.

El principal problema parte por el débil o nulo control en las fronteras exteriores de la Unión lo que genera que los inmigrantes irregulares tengan acceso al libre tránsito que brinda el acuerdo Schengen en territorio europeo.

Dimitris Avramopoulos (Europea C. , 2016), Comisario de Migración, aclara que frente a la debilidad de la Unión Europea se debe de subsanar las graves deficiencias detectadas en nuestras fronteras exteriores, pues obviamente nuestro espacio interior libre de controles fronterizos solo puede existir si protegemos firmemente nuestra fronteras exteriores, por lo tanto la debilidad en si, no es la apertura de las fronteras interiores sino el deficiente control existente en las fronteras exteriores de la Unión Europea.

Además, en el Comunicado de prensa emitido por la Comisión Europea (Europea C. , 2016), se calcula un aproximado de cuanto es lo que costaría la desaparición del espacio Schengen para la Unión Europea y sus miembros. Se calcula que los costos inmediatos serian entre 5000 y 18,000 millones de euros. Por lo tanto, las modificaciones que se le plantea hacer o el cierre del espacio serian contraproducentes por el mensaje que se mandaría ya que denotaría que no tienen la capacidad de cómo bloque enfrentar la problemática que conlleva una crisis humanitaria tan grande como la que se está viviendo en Europa. 


\section{- Protagonismo Frontex}

Desde el 2015 la Agencia Frontex ha cobrado un protagonismo importante, pero ¿A qué se debe este "protagonismo? El protagonismo que cobra la Agencia Europea de la Guardia de Fronteras y Costas (Frontex) es debido al gran número de entradas de refugiados o inmigrantes irregulares a territorio europeo producto de la crisis que asolaba y asola a los vecinos del continente.

La importancia o "protagonismo" se refleja claramente en el gran aumento que ha tenido el presupuesto de la Agencia. Este aumento en el presupuesto lo que buscaba principalmente era incrementar la presencia de efectivos del Frontex en las fronteras interiores de los países europeos, para de esta forma evitar que los refugiados y/o inmigrantes irregulares transiten libremente y soliciten asilo en otros países, aun cuando ya tengan iniciado un proceso en otro estado, no obstante, también se buscó fortalecer el control de las fronteras exteriores.

Cabe resaltar que la OTAN y FRONTEX en el año 2016 sellaron un acuerdo de cooperación contra las mafias de refugiados con sistemas en tiempo real para poder actuar de inmediato ante el incesante flujo migratorio que llega a la Unión Europea, esta ayuda se dará principalmente en el sector del Mar Egeo lo que permitirá a uno de los países mas afectados como Grecia tener capacidad de repuesta y evitar y/o controlar el flujo irregular de los refugiados.

Por lo tanto, la evolución en el rol de la Agencia es producto de la magnitud de la crisis que se vive en el continente, la importancia actual es gracias a los constantes nuevos retos que proponen las fronteras de la Unión Europea, esto debido a que se encuentran constantemente vulneradas por los refugiados y los inmigrantes irregulares. 
Figura 8: Evolución del presupuesto de Frontex. Fuente: Ruiz y Brunet (2018)
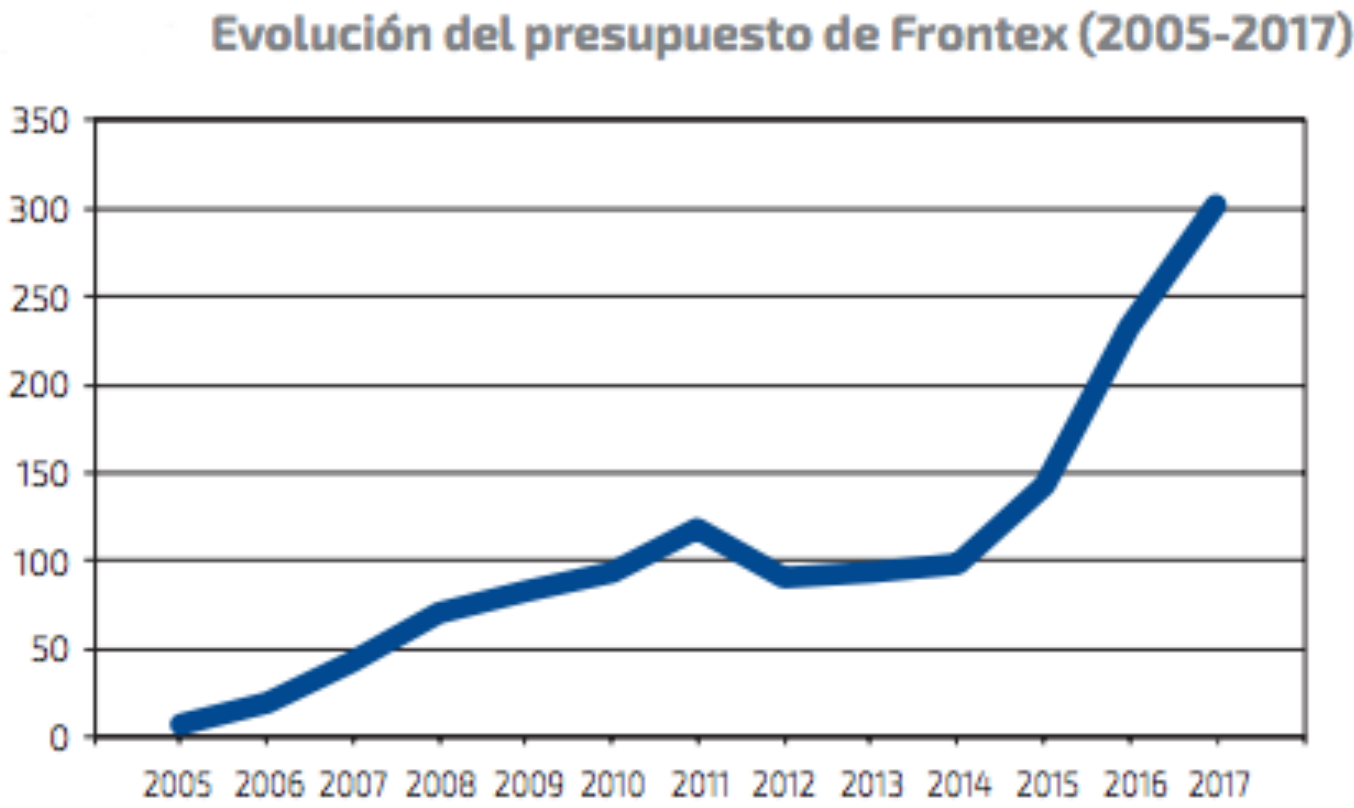

Las consecuencias sociales en la Unión Europea debido a la crisis de los refugiados es un tema muy sensible y que explica muchos aspectos que son relevantes para la investigación. Podemos observar el crecimiento de los partidos de extrema derecha, pero ¿Por qué estos partidos están cobrando tanta importancia en los países de la Unión Europea? Es por que también hay una aceptación relativa por parte de los habitantes que de forma directa o indirecta apoyan este tipo de movimientos. El sentimiento anti inmigratorio se da por temas muy puntuales, la propagación de la cultura Islámica en territorio europeo y los atentados terroristas perpetrados por disidentes pertenecientes a ISIS y que la sociedad europea asocia de forma directa con los refugiados, es necesario agregar que la cultura islámica no apoya o fomenta estos atentados causados por extremistas si no que es utilizada por ciertos personajes para desviar las creencias y hacer llegar al fanatismo con propósitos personales no ligados a la religión o cultura.

Por otro lado, la presencia Islámica en Europa es tan fuerte que la Unión Europea respalda la creación de mezquitas oficiales del islam. Este es un punto sensible que la Unión Europea maneja adecuadamente, ya que a través de esto contribuye a la no aparición de mezquitas "clandestinas" que apoyen el extremismo islámico y/o otras ideas radicales asociadas a esta 
religión, lo cual no necesariamente implica que no existan, pero apoya sustancialmente a contrarrestarlas.

\section{- Efectos de los Atentados Terroristas}

En este punto nos enfocaremos en los atentados terroristas realizados durante la crisis de los refugiados en estudio, para así poder resaltar a que grupos se les ha atribuido o se han atribuido ellos mismos estos incidentes.

La importancia en cuanto a los atentados terroristas es que la gran mayoría fueron ejecutados por musulmanes fieles a ISIS, no obstante, cabe resaltar que la gran mayoría que llevo a cabo estos atentados no fueron si no musulmanes que ya residían en territorio europeo.

Han sido perpetrados muchos atentados desde que los movimientos terroristas cobraron un papel importante en el sistema internacional, enfocándonos en la época y lugar de estudio podemos encontrar una cantidad muy grande de sucesos.

En el siguiente cuadro podemos observar los atentados que han tenido lugar en Europa y en que intervalos de años. Las cifras son alarmantes y podemos resaltar a Francia como el que más atentados sufrió desde el 2015, seguido por Bélgica, Alemania, España, entre otros.

Estos acontecimientos han tenido un impacto muy grande dentro de la sociedad de la Unión europea, debido a que creció el sentimiento de inseguridad junto con el de rechazo a todo tipo de migración proveniente de países exteriores al territorio europeo.

La asociación que se hace en cuanto a reconocer quienes son los autores de estos atentados no necesariamente es exacta pero las variables que no son expuestas hacen que esta sea muy fácil de manipular, y es gracias a esto que partidos políticos xenófobos están cobrando protagonismo dentro de los países miembros de la Unión Europea. 


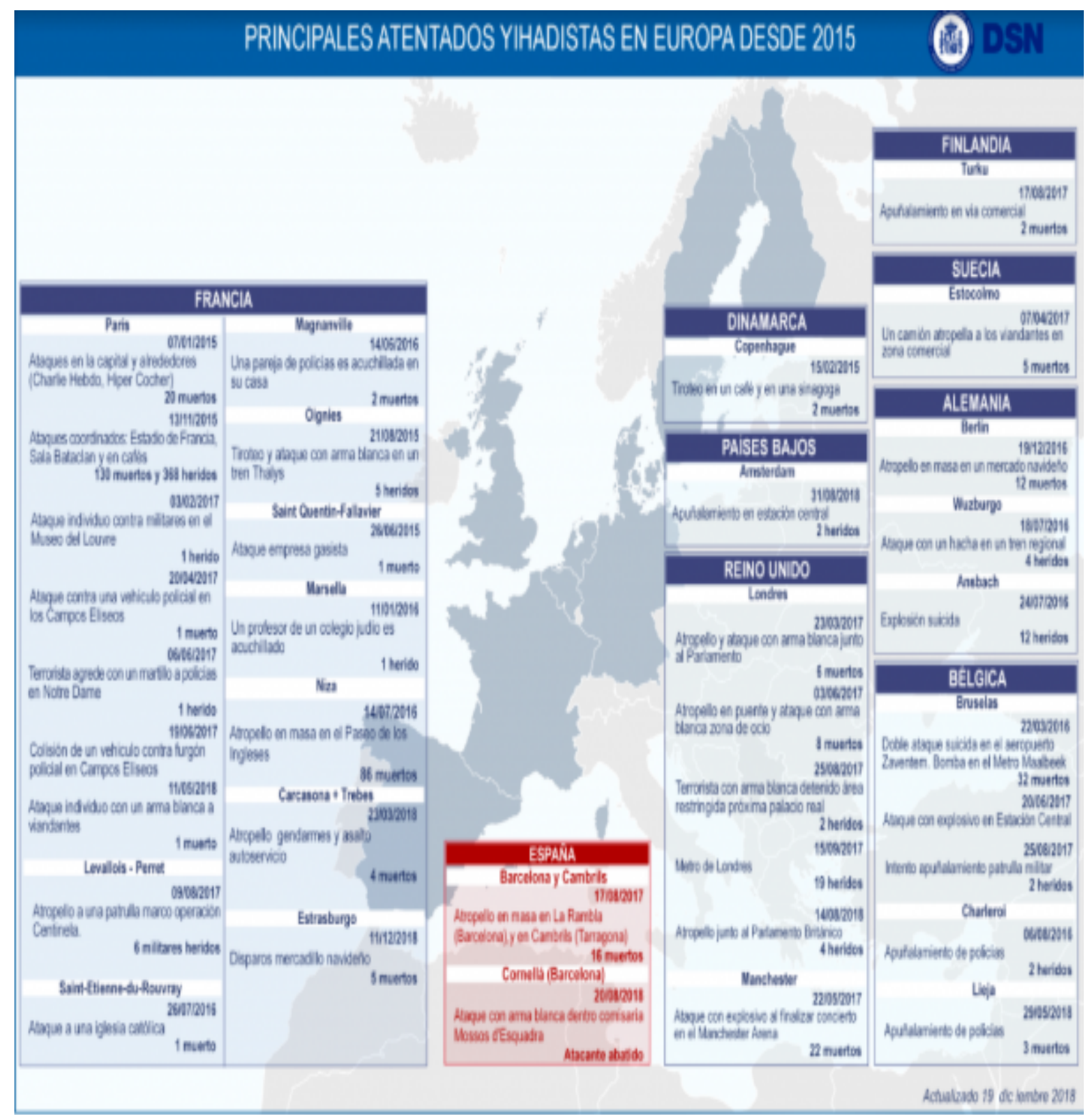

Figura 9: Principales atentados. Fuente: Ramos (2019)

\section{- Plan de Acción Conjunto (Negociación Unión Europea - Turquía)}

El Plan de Acción Conjunto entre ambos actores se puso en marcha en noviembre de 2015, este plan intento fortalecer la cooperación internacional entre ambos actores en los temas relacionados a la migración la cual provenía en su mayoría de Siria.

El Primer Vicepresidente de la Comisión declaro en aquel entonces: 
"Valoro positivamente las medidas ya adoptadas por las autoridades turcas para contener el flujo de migrantes irregulares, como la de la apertura de mercado laboral a los refugiados sirios. No debemos hacernos ilusiones de que la crisis de los refugiados vaya a acabar antes de que se aborden sus causas profundas, en particular el mantenimiento de la guerra y las atrocidades en Siria, de forma definitiva. Seguiremos trabajando de forma conjunta con nuestros socios turcos para ejecutar íntegramente el Plan de Acción Conjunto de forma que podamos cumplir los compromisos asumidos para poner orden en los flujos migratorios, también por lo que respecta a la lucha contra los traficantes y las salidas irregulares de Turquía hacia Europa" (Comision Europea, 2016)

El Plan de Acción Conjunto fundamentalmente buscaba terminar con el flujo irregular de salidas de refugiados de suelo turco hacia territorio de la Unión Europea como una suerte de tapón en la ruta del mediterráneo oriental. Tras realizar un primer pago de 3000 millones de euros se esperaban los resultados por parte del país turco en cuanto al refuerzo en el control de los puertos y de las estrategias que ofrecía su guardia costera en caso las fronteras se vieran vulneradas. 


\section{Destino del dinero de la UE en Turquía}

En millones de euros

Primer tramo

3.000 millones
Segundo tramo

3.028 millones

Auditoría

$7 \%$

$2 \%$

$2 \%$

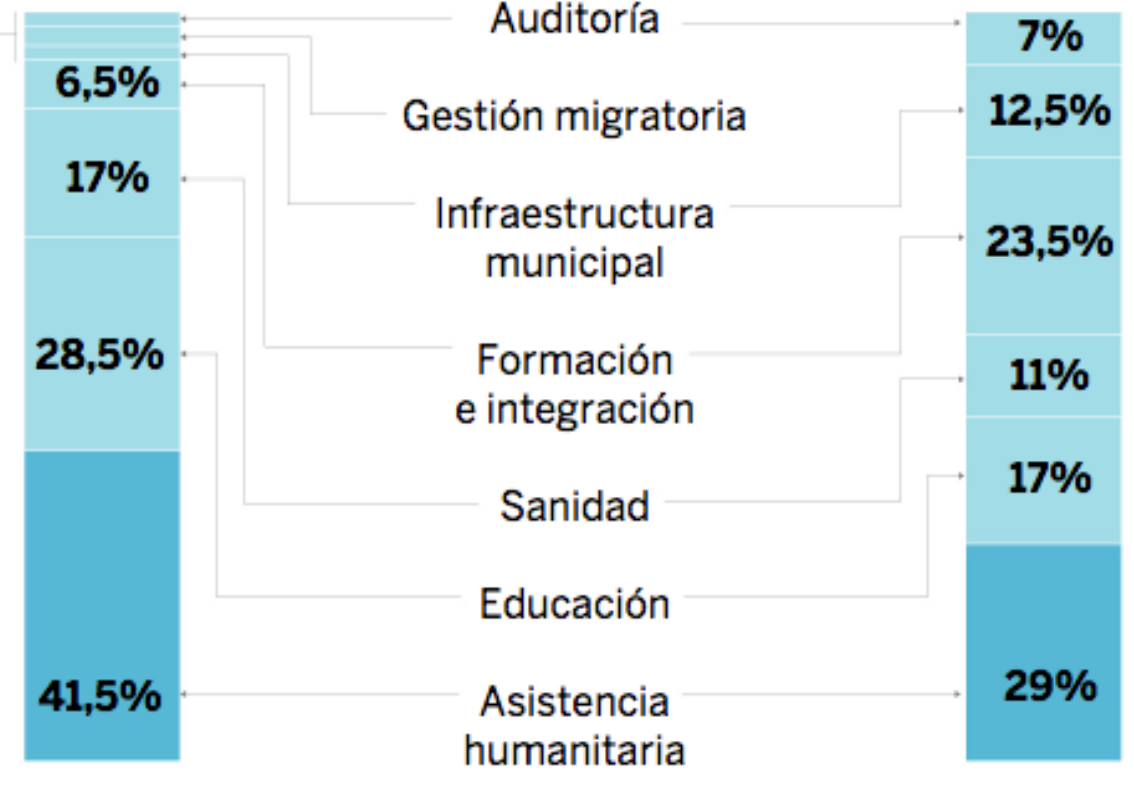

Fuente: Fuente: elaboración propia a partir de datos de la Comisión Europea.

EL PAÍS

Figura 10: Destino del dinero de la UE en Turquía. Fuente: Mourenza (2019)

Sin embargo, este convenio entre ambos países también impulsaba en cierta forma, a través de la inversión realizada, otorgar las necesidades básicas que necesitaban y necesitan los refugiados, pero en territorio turco, con la creación de "campos" en las cuales ellos podían acceder a tener lugares en donde vivir además de la construcción de escuelas y hospitales con los cuales se encuentren abordadas estas necesidades.

Es importante resaltar las negociaciones que se sostuvieron entre el bloque europeo y el país de Turquía debido a que como ya ha sido costumbre en el bloque los países en general no estuvieron del todo satisfechas tras la política que se adoptó en estas reuniones. 
Los países tales como los pertenecientes al Visegrado siempre se han mostrado en contra de las soluciones temporales y la aceptación en su totalidad de la gran ola de refugiados que ha ido entrando en los últimos años. Por lo tanto, el plan de acción conjunto entre estos actores lo único que lograba en síntesis era y es la retención del flujo migratorio proveniente de la ruta del Mediterráneo Oriental.

La retención del flujo migratorio en Turquía lo único que logra es retrasar y disminuir mas no eliminar la entrada de refugiados a territorio europeo además en cierta parte expone al bloque a la disposición de un estado "outsider".

\section{- Posición países del Visegrado}

El Grupo del Visegrado nació en 1335 como una coalición en contra de la dinastía Habsburgo, esta coalición incluía en aquel entonces a Hungría, Checoslovaquia y Polonia.

Tras la caída del muro de Berlín y la caída de la URSS este grupo decidió volver a unirse con una meta en común la cual era ser parte en aquel entonces de la Comunidad Económica Europea, cabe resaltar que, tras la separación del Estado de Checoslovaquia, el grupo paso a ser conformado por Hungría, Polonia, República Checa y Eslovaquia. El Grupo del Visegrado siempre ha mostrado una posición común entre sus miembros y es que eso le aumenta el peso en las decisiones que deciden tomar debido a que son 4 países los que lo conforman (Bosques, 2014).

La posición del grupo del Visegrado siempre ha sido opositora ante las políticas de apertura por parte de la Unión Europea sobre todo en el sector migración.

Cabe resaltar que a lo largo de mi investigación tuve el privilegio de entrevistar a unos de los representantes de República Checa en Perú, mencionó esto debido a que tras haber tenido esta entrevista pude conocer a fondo la posición y el porqué de esta. 
En la entrevista realizada a Pavel Bechny, mencionó que:

Estamos frente a una situacion que Europa tiene estas zonas migratorias y mucha gente ingresa sin ningun tipo de control, yo creo que todos Europa, UE y nosotros estamos abiertos para una migracion legal, controlada, dirigida pero no con la migracion ilegal, migracion descontrolada, entonces esto si se discute mucho y por ejemplo mi pais estuvo un poco critico respecto a esas politicas de demasiada apertura hacia inmigrantes, sistema de cuotas obligatorias, nosotros dijimos no, tenemos que atacar el problema, tenemos que atacar el problema afuera, no resolverlo ya cuando esta nuestra casa" que despues tenemos que, bueno se aprovecha de la situacion, mucha gente piensa que imponer otras creencias, otras culturas y eso crean fricciones por supuesto, entonces yo pienso que ese tema de migracion es un grave problema para Europa hay que resolverlo con urgencia. (Velasquez, 2019)

También Pavel Bechny señala que: "Ese tema de migracion es un grave problema para Europa hay que resolverlo con urgencia" es una frase que en opinión refleja el sentir de un gran porcentaje de la poblacion europea.

Los países del Visegrado centran su posición en el resguardo de las fronteras exteriores de la Unión Europea y se oponen firmemente a la gran ola inmigrante proveniente de Siria y otros países musulmanes.

Pero ¿A qué obedece esta oposición tan firme? Esta oposición evita poner en riesgo la cultura y la religión del grupo, esto debido a que como ya se ha podido evidenciar, en otros países de la Unión Europea que cuentan con mayor número de refugiados, la presencia de la cultura musulmana ha crecido de forma exponencial. 


\section{- Cooperación Unión Europea - Libia}

Quizás una de las políticas más criticadas tanto por la prensa mundial como de los Organismos Internacionales, las negociaciones que se mantuvieron en el año 2016 entre la Unión Europea y Libia significaron el regreso de muchos refugiados que intentaban huir de sus países por la ruta del Mediterráneo Central.

Una inversión de 130 millones de euros para convertir a Libia en su nuevo muro frente a la migración proveniente de los países del África Subsahariana. A través de esta inversión se buscó que los refugiados provenientes de países del África Subsahariana se establecieran en Libia y este mismo asegure la protección de los derechos humanos, se redoblo la capacidad territorial que cubría anteriormente la guardia costera Libia para de esta forma evitar que tengan acceso a algún rescate por parte de autoridades europeas lo cual suponía su posterior ingreso al viejo continente. (RT, 2017). En el siguiente mapa se muestra de donde provienen y que rutas desean tomar para finalmente salir por la ruta del Mediterráneo Central hacia territorio europeo. 


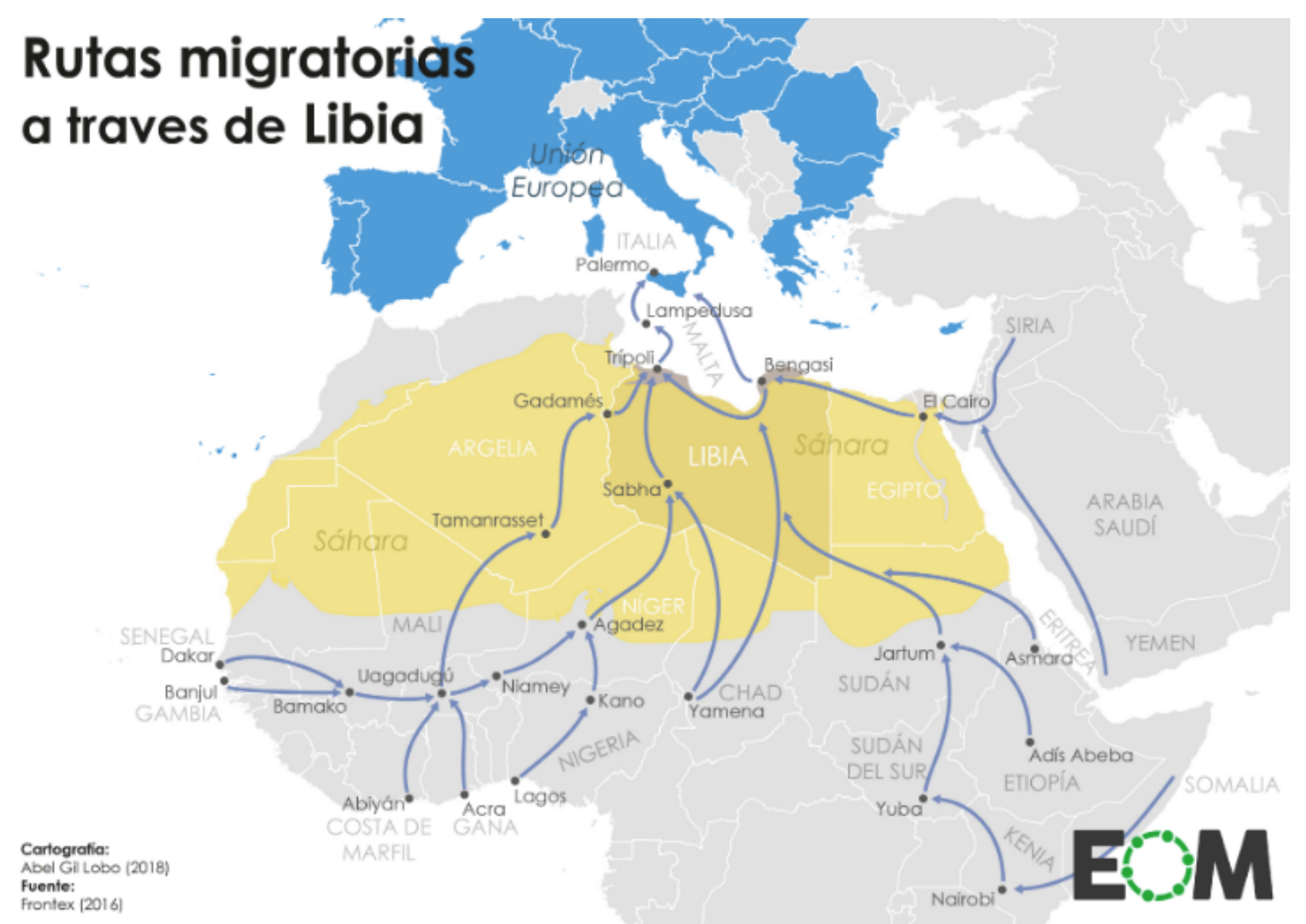

Figura 11: Rutas migratorias a través de Libia. Fuente: (EOM, 2020)

\section{- Construcción de muros en Europa}

Uno de los problemas que dificulta en cierta parte la adopción de políticas comunes en la Unión Europea para hacer frente a la crisis de los refugiados, son las acciones en particular que han tomado los estados para salvaguardar su seguridad nacional y proteger sus intereses nacionales. Es así como países miembros de la Unión Europea desde el inicio de la crisis han construido muros para imposibilitar el acceso de los refugiados hacia su territorio, podemos observar que la construcción de estos ha crecido exponencialmente desde el año 2015, el cual fue el año mas critico en entradas de refugiados. 
Tabla 2: Muros de los países de los estados miembros de la Unión Europea, Schengen y Macedonia 1990-2017

\begin{tabular}{|c|c|c|c|}
\hline País constructor & Pais contra el que se hace & Alio de inicio & Razones \\
\hline España (1) & Marruecos (Ceuta) & 1993 & Inmigración \\
\hline Esparia (2) & Marruecos (Melil.a) & 1996 & Inmigración \\
\hline Grecia (3) & Turquía & 2012 & Inmigración \\
\hline Eslovaquia (4) & $\begin{array}{l}\text { Ciudades internas: Kosice, Velka Ida, } \\
\text { Ostrovany }\end{array}$ & 2013-en construcción & Segregación, seguridad \\
\hline Bulgaria (5) & Turquía & 2013 & Inmigración \\
\hline Hungría (6) & Croacia & 2015 & Inmigración \\
\hline Hungría (7) & Serbia & 2015 & Inmigración \\
\hline Macedonia (8) & Grecia & 2015 & Inmigración \\
\hline Austria (9) & Eslovenia & 2015 & Inmigración \\
\hline Eslovenia (10) & Croacia & 2015 & Inmigración \\
\hline Reino Unido (11) & Francia (puerto de Calais) & 2015 & Inmigración \\
\hline Letonia (12) & Rusia & 2015 & $\begin{array}{l}\text { Seguridad, tensión territorial, contrabando, } \\
\text { inmigración }\end{array}$ \\
\hline Noruega (13) & Rusia & 2016 & Seguridad, Inmigración \\
\hline Estonia (14) & Rusia & $2016-2017$ & Seguridad, tensión territorial, inmigración \\
\hline Lituania (15) & Rusia & 2017 & Seguridad, tensión territorial, inmigración \\
\hline
\end{tabular}

"Se incluye la República de Macedonia a pesar de no ser miembro de la UE ni de Schengen por ser parte esencial de la Ruta de los Balcanes que atraviesa los pa'ses de la UE. Fuente: Elaboración propla a partir de las fuentes: (1) (2) (3) (5) (7) Economist, The (2015), (4) Herrera, Manuel(9-2-2017)(6) AAKESEVVIC, R. yTATALOVLC, 5. (2016), (8) (9) (10) (11) (13) ACNUR (2017) (12) (14)(15) Jones, (2017: 87)

Fuente: Ruiz y Brunet (2018) 
Tabla 3: Muros Fronterizos España - Marruecos

\begin{tabular}{|l|l|}
\hline PAÍS CONSTRUCTOR & PAís FRONTERIzo \\
\hline ESPAÑA (1) (2) (3) & MARRUECOS CEUTA \\
\hline Separación & $\begin{array}{l}\text { Estados de España y de } \\
\text { Marruecos (frontera no } \\
\text { reconocida por Marruecos) }\end{array}$ \\
\hline $\begin{array}{l}\text { Total frontera entre ambos } \\
\text { espacios }\end{array}$ & $6,3 \mathrm{~km}$ \\
\hline Barreras físicas (distancias) & Largo: 8,3 km (4) Alto: 6 m (4) \\
\hline Año de inicio & 1993 (1) \\
\hline Año de finalización & 2005 (1) \\
\hline Razones para su construcción & Inmigración, contrabando (1) \\
\hline $\begin{array}{l}\text { Delimitación geográfica } \\
\text { que pretende }\end{array}$ & $\begin{array}{l}\text { Nacional, Unión Europea- } \\
\text { África, entrada en la UE, } \\
\text { entrada en Schengen }\end{array}$ \\
\hline Estado de militarización & $\begin{array}{l}\text { Dos vallas de alambre (4). } \\
\text { Detectores de movimiento, } \\
\text { cámaras de video e infrarrojas } \\
\text { y17 torres de control (4)y } \\
\text { cámaras de video (sistema de } \\
\text { vigilancia SIVE) (5) }\end{array}$ \\
\hline
\end{tabular}

Elaboración propia a partir de las siguientes fuentes:

(1) Economist. The (2015), (2) ACNUR (2017), (3) Jones, Reece (2016: 87)

(4) Alscher, Stefan (2005: 11), (5) Alscher, Stefan (2005: 12), (6) Picazo, Belén (20-11-13)

Fuente: Ruiz y Brunet (2018)

Tabla 4: Muros Fronterizos España - Marruecos

\begin{tabular}{|c|c|}
\hline PAIS CONSTRUCTOR & PAIS FRONTERIZO \\
\hline ESPAÑA (1) (2) (3) & MARRUECOS MELILLA \\
\hline Separación & $\begin{array}{l}\text { Estados de España } \\
\text { y Marruecos }\end{array}$ \\
\hline $\begin{array}{l}\text { Total frontera entre ambos } \\
\text { espacios }\end{array}$ & $9,6 \mathrm{~km}$ \\
\hline Barreras físicas (distancias) & Largo: $10 \mathrm{~km}$ (5) Alto: $6 \mathrm{~m}$ (4) \\
\hline Año de inicio & 1996 (1) (3) \\
\hline Año de finalización & $2007(6)$ \\
\hline Razones para su construcción & Inmigración, contrabando (1) \\
\hline $\begin{array}{l}\text { Delimitación geográfica } \\
\text { que pretende }\end{array}$ & $\begin{array}{l}\text { Nacional, Unión Europea- } \\
\text { Africa, entrada en la UE, } \\
\text { entrada en Schengen }\end{array}$ \\
\hline Estado de militarización & $\begin{array}{l}\text { Triple valla, alambras, } \\
\text { concertinas (alambre de púas), } \\
\text { sirga tridimensional ( } 3 \text { metros } \\
\text { de alto an̉adida en } 2007)(6), \\
\text { alarmas y zanja de tierra de } \\
\text { dos metros de profundidad } \\
\text { (6). Cámaras de vigilancia } \\
\text { (sistema de vigilancia SIVE) } \\
\text { (5), detectores de movimiento, } \\
\text { sensores opticos y acústicos, } \\
\text { torres de control y más de } 70 \\
\text { cámaras de vigilancia (5) }\end{array}$ \\
\hline
\end{tabular}

Elaboración propia a partir de las siguientes fuentes:

(1) Economist, The (2015), (2) ACNUR (2017), (3) Jones, Reece (2016: 87)

(4) Alscher, Stefan (2005: 11), (5) Alscher, Stefan (2005: 12), (6) Picazo, Belén

(20-11-13)

Fuente: Ruiz y Brunet (2018) 
Tabla 5: Muros Fronterizos Grecia - Turquía

\begin{tabular}{|c|c|}
\hline PAÍS CONSTRUCTOR & PAÍS FRONTERIZO \\
\hline GRECIA (1) (2) (3) & TURQQUÍA \\
\hline Separación & Estados turco y griego \\
\hline $\begin{array}{l}\text { Total frontera entre ambos } \\
\text { espacios }\end{array}$ & $206 \mathrm{~km}$ \\
\hline Barreras físicas (distancias) & Largo: 12 km (4)(5) Alto: 4 m (6) \\
\hline Año de inicio & $2012(1)$ \\
\hline Año de finalización & $2012(1)$ \\
\hline Razones para su construcción & Inmigración (1) \\
\hline $\begin{array}{l}\text { Delimitación geográfica } \\
\text { que pretende }\end{array}$ & Nacional \\
\hline Estado de militarización & $\begin{array}{l}\text { Valla de alambre y cemento } \\
\text { con alambre de espino } \\
\text { (7), sistemas electrónicos } \\
\text { de vigilancia, guardias de } \\
\text { fronteras, drones, cámaras } \\
\text { de visión nocturna (6) }\end{array}$ \\
\hline \multicolumn{2}{|c|}{$\begin{array}{l}\text { Elaboración propia a partir de las siguientes fuentes: } \\
\text { (1) Economist, The (2015), (2) ACNUR (2017), (3) Jones, Reece (2016: 87), } \\
\text { (4)Greece plans Turkey border fence to tackle migration (4-1-11), } \\
\text { (5) Stroobants y Perrier (11-1-11), (6) Associated Press (6-1-12), (7) Kakissis } \\
\text { Joanna (7-1-11) }\end{array}$} \\
\hline
\end{tabular}

Fuente: Ruiz y Brunet (2018)

Como se puede apreciar en los cuadros anteriores denotamos un gran crecimiento en la construcción de muros no en los últimos años en algunos casos, pero los motivos por los que fueron colocados son similares.

Cabe recalcar que estas son medidas que son muy criticadas por parte de la población mundial debido a que son de interpretación muy negativa hacia los países que los construyen ya que implican el total rechazo en cuanto al ingreso de migrantes provenientes del país vecino o fronterizo, situaciones similares se han vivido entre Estados Unidos y México y que causo un revuelo importante en la prensa mundial. 


\section{- Desnutrición en África}

Cabe resaltar la desnutrición en África como un factor social que de forma directa contribuye al flujo migratorio que llega a territorio europeo, esto debido a que en gran porcentaje la migración en África es motivada por temas como las sequias, estas se suscitan debido al gran cambio climático que se esta dando a nivel mundial el cual tiene como repercusión directa la escasez en la producción de alimentos. La lucha contra la desnutrición es un tema de gran importancia a nivel global tal es así su repercusión que es una de las principales causas del flujo migratorio proveniente de África, el apoyo de la Unión Europea en este sector puede ser fundamental para que los ciudadanos de estos países no decidan migrar.

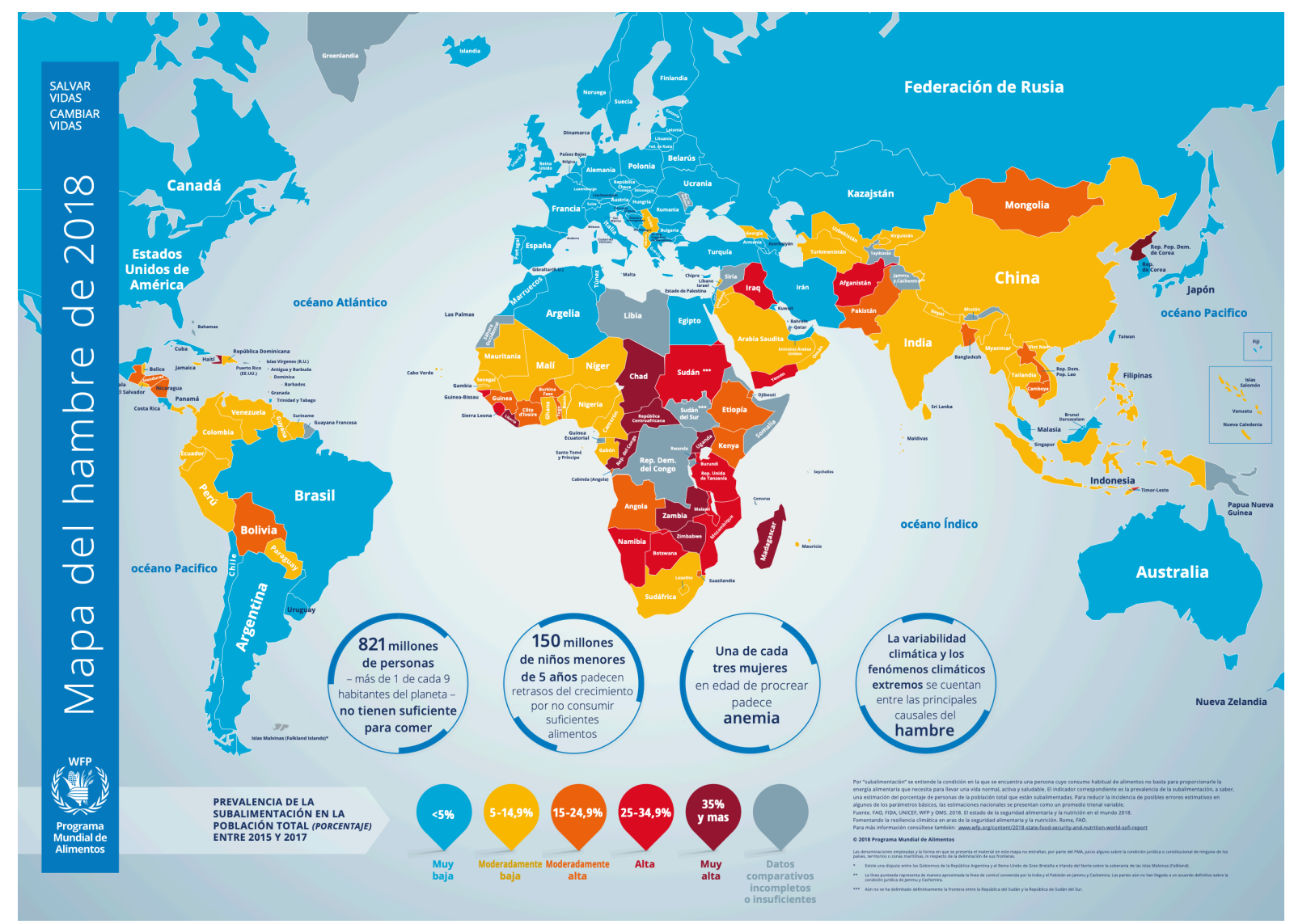

Figura 12: Mapa del hambre de 2018. Fuente: ONU Programa Mundial de Alimentos (PMA). 


\section{CAPÍTULO VI: CONCLUSIONES}

\section{Conclusiones}

- El sistema de imposición de cuotas de refugiados, pagos a Turquía, construcción de muros y métodos similares a estos, han dejado en evidencia la poca solidaridad por parte del bloque europeo con respecto a la crisis que viven los estados vecinos. Esta representa una seguidilla de errores en la búsqueda de una solución diplomática en la que sus miembros estén de acuerdo por unanimidad. Es importante resaltar que desde mi opinión a través de la investigación estos desaciertos han afectado la imagen que proyecta la Unión Europea al sistema internacional como organismo de Integración Regional.

- La crisis de los refugiados ha puesto en evidencia las falencias de la Unión Europea, una de las principales es la "desunión" entre sus miembros, esto debido a que la realidad de cada país es diferente por lo cual las medidas a plantear son asequibles para algunos miembros mientras que para los de menor poder económico representan un gran esfuerzo. Podemos evidenciar como Alemania siempre estuvo a favor en cuanto a la llegada de los refugiados además de ser el principal impulsor de la imposición de cuotas por países esto debido a su gran capacidad económica y preparación social. La otra cara se ha visto representada por los países que conforman el grupo de Visegrado los cuales han mostrado una posición hermética en cuanto a las políticas que se han propuesto, poniendo en primer lugar los intereses nacionales y el rol del estado en el sistema internacional.

- Las autoridades de la Unión Europea y de los países miembros se ven obligados a tener en cuenta los efectos políticos de la llegada de los refugiados. El problema radica en la difícil obra de crear una política común para los estados en el que todos accedan por un bien común sin que los intereses estatales sean perjudicados y al mismo tiempo sin demostrar la perdida 
de interés en la protección de los derechos humanos y en los valores que establece fomentar el bloque, una tarea muy difícil debido a la gran cantidad de actores pertenecientes.

Es necesario encontrar una política que acabe con la crisis de los refugiados pero que no de la espalda a los derechos humanos para que de esta forma no den oportunidad a la propagación de pensamientos extremistas aprovechando la coyuntura del conflicto. Es muy importante analizar todas las consecuencias de la crisis de los refugiados ya que un nacionalismo tan vivo como el que se puede presenciar en territorio de la Unión Europea asoma una pequeña y remota posibilidad de que lo que hemos vivido en un pasado que termino con una Europa devastada pueda volver a ocurrir.

- La investigación me ayudó a conocer la situación actual que se vive en Europa, tener una apreciación más exacta sobre lo que viven los refugiados en su largo camino hacia Europa. Además de ver como una crisis de estas características puede afectar tanto a la Unión Europea que es el Organismo Internacional más logrado del mundo, que lleva muchos años siendo uno de los más estables y con índices de aprobación aceptables.

Es necesario recalcar esto debido a que es importante contar con una planeación y prevención más eficaz, no obstante, en cuanto a las normas que pueden ser sujeto de conflicto fuera de la esfera de influencia de la Unión Europea deben gozar de cierta flexibilidad para adaptarlas de forma más rápida y efectiva.

- La solución del problema se encuentra tanto fuera como dentro de la Unión Europea, ya que una buena política migratoria y la adaptación de las normas internacionales relacionadas con esta crisis no bastara para erradicar este problema, es necesario también hallar estrategias que influyan en el bienestar de estas personas dentro de sus países que fomenten la paz y el desarrollo económico.

- Las medidas políticas que se previeron para evitar o en alguna forma controlar la intensidad o gravedad de una crisis de refugiados, como el Convenio de Dublín, la aparición del 
Frontex y las capacidades que otorgaba el Acuerdo de Schengen en cuanto al cierre temporal de fronteras no fueron bien planteadas por parte de las autoridades de la Unión Europea. Ciertas características en algunos de estos casos, como la opción del primer país de llegada en el Convenio de Dublín, la existencia de un Frontex con un presupuesto mas que limitado y un Acuerdo de Schengen en el que se unieron países que aun no se encontraban preparados fueron importantes causales de el gran impacto que tuvo el flujo migratorio que comenzó en 2015, tanto en la sociedad como en la economía y política de la Unión Europea.

- Un porcentaje de los refugiados son causa también del cambio climático, esto debido a las sequias ocurridas en muchos de los países del África, como consecuencia de estas sequias la producción de alimentos es prácticamente nula, esto trae consigo un gran índice de desnutrición en África, lo cual junto a los conflictos armados son los mas grandes motivadores de migración en este sector geográfico. La Organización de las Naciones Unidas califica a muchos de los países de África con un índice de seguridad alimenticio muy bajo esto se manifiesta en la presentación que hace anualmente en el mapa del hambre. 


\section{RECOMENDACIONES}

\section{Recomendaciones}

- La Unión Europea a través de programas de apoyo y asistencia internacional debe fomentar el desarrollo de los estados mas subdesarrollados que forman parte de su esfera de influencia geográfica, esto debido a que la gran ola migratoria proviene de este sector. Este es uno de los principales factores por los que muchos habitantes de estados colindantes han decidido migrar hacia territorio europeo, no obstante, es necesario recalcar que la curva de incremento de migración hacia territorio europeo aumento en el año 2015 por los incesantes conflictos que se recrudecían en Siria, Afganistán o Irak.

La extrema pobreza y los conflictos son variables muy importantes en cuanto a la continuidad de esta crisis, por lo que la creación de instituciones financiadas por parte de la Unión Europea que fomenten el trabajo, la educación y proyectos auto sostenibles en estos países o en países fronterizos ayudaría de forma sustancial a que las personas puedan encontrar la calidad de vida que quieren dentro de sus fronteras.

- Las políticas que se desean adoptar para hacer frente a la crisis deben garantizar el respeto de los derechos humanos, estos deben garantizarse tanto en los campos de refugiados que se encuentran en territorio de la Unión Europea como en los países de transición, ya que gran porcentaje del numero de personas que llegaron a los campos de refugiados aseveran serias violaciones a los derechos humanos de mujeres y niños.

Se debe redoblar esfuerzos en la lucha contra las mafias de trafico de personas que existe en los países con frontera marítima a tierra europea y con países que son de transición terrestre. Es vital para fortalecer la imagen del bloque europeo luchar contra los abusos que se están cometiendo y ser principales defensores de los derechos humanos, para que 
demuestren la solidaridad del bloque para con los países fronterizos, es ahí en donde la influencia y el rol del bloque europeo en el sistema internacional cobrara mayor importancia.

- La actualidad de los miembros pertenecientes a la Unión Europea es diferente por lo que las políticas y/o medidas que se propongan deben ser proporcionales a sus capacidades tanto económicas como sociales, por lo tanto, una de las mas grandes dificultades que atraviesa el bloque al adoptar una política común para poder finiquitar esta crisis es el de encontrar políticas que fomenten la contribución equitativa según la capacidad de cada actor. Por lo que se debería proponer políticas de contribución igualitaria, según la capacidad de cada actor, de manera que apoye en la disminución de flujo migratorio irregular en los países ribereños y así acabar con los cuestionamientos por parte de algunos actores de la Unión Europea.

- Otra de las principales dificultades que afronta esta crisis y que empeora el panorama es que los países colindantes, que es de donde proviene la mayoría del flujo migratorio, atraviesan también problemas que escapan de la capacidad humana como lo es el cambio climático que ha traído consigo enormes sequias en distintas ciudades y que se prevé empeorara en los próximos años, la cual es una de las principales causas que incitan a la migración de los pobladores de este sector geográfico. Los compromisos adquiridos en el tratado de Paris son fundamentales para poder acabar con esta problemática que atañe a todo el mundo.

- Se debe buscar salidas políticas que contribuyan a la sociedad de la Unión Europea es decir que, a través de medidas políticas se impulse un movimiento solidario por parte de la sociedad europea, que como consecuencia unifique a la población de todos estos actores, para luchar contra la crisis de los refugiados. Se debe evitar que avance el crecimiento de la 
extrema derecha o el crecimiento de la xenofobia incentivando a la población a la aceptación y al apoyo de los refugiados que son admitidos en territorio europeo.

- La Unión Europea como órgano de integración regional ya estableció sus bases y a estas las complemento con instituciones y órganos legislativos, los cuales funcionan en beneficio del bloque y sirven para hacer frente a las dificultades que se susciten en la comunidad, por lo que la forma apropiada de hacerle frente a una crisis como esta es reforzar las bases del órgano, pero haciéndolo evolucionar adaptando el marco normativo existente a las exigencias que se presenten en la actualidad.

- Las medidas políticas existentes para hacer frente a un flujo migratorio masivo como el que comenzó en 2015 fueron mal elaboradas ya que no fueron capaces de adaptarse a escenarios tan extremos como este, esto debido a la integración regional que se dio post Schengen y las regulaciones que trajo consigo el Convenio de Dublín fueron capaces de contener y adecuar en su momento la migración en menor capacidad, mas no tuvieron la misma efectividad y la capacidad de adecuarse a situaciones tan extremas como las que se presentaron los últimos años.

- Es importante tomar valoraciones al presente trabajo, ya que como es conocida en la coyuntura peruana, atravesamos un flujo migratorio que muy pocas veces se ha visto, esto ha traído consigo problemas sociales que han recalado en la seguridad de la población ya sea con el incremento de la delincuencia, aumento en las competencias al conseguir empleo, devaluación de la mano de obra en algunos sectores con poca regulación, entre otros. Es decir, las decisiones que adoptemos para solucionar o de alguna forma poder aplacar las problemáticas que van apareciendo, por la llegada masiva de extranjeros al país, debe ser consensuada y respetando los derechos humanos de todos los actores envueltos. Por lo que como sociedad debemos tomar decisiones sensatas que contribuyan al desarrollo y a la buena imagen del Perú en el sistema Internacional. 


\section{BIBLIOGRAFIA}

ACNUR Comité Español. (21 de Septiembre de 2018). ¿Qué es el Convenio de Dublin? Obtenido de ACNUR Comite Español: https://eacnur.org/blog/convenio-de-dublinque-es-tc_alt45664n_o_pstn_o_pst/

ACNUR. (s.f.). Manual de procedimientos y criterios para determinar la condición de refugiado en virtud de la convención de 1951 y el protocolo de 1967 sobre el Estatudo de los Refugiados. Obtenido de https://www.acnur.org/fileadmin/Documentos/BDL/2011/7575.pdf

Amsterdam, T. d. (1997). Unión Europea. Obtenido de https://europa.eu/europeanunion/sites/europaeu/files/docs/body/treaty_of_amsterdam_es.pdf

Asilo. (2019). Obtenido de https://ec.europa.eu/eurostat/statisticsexplained/index.php?title=Asylum_statistics/es\#Pa.C3.ADses_de_destino:_los_princi pales.2C_Alemania.2C_Italia_y_Francia

Bosques, C. d. (29 de Septiembre de 2014). Primera Reunion Mexico-Grupo Visegrad. Obtenido de Centro de Estudios Internacionales Gilberto Bosques: https://centrogilbertobosques.senado.gob.mx/docs/ficha290914.pdf

Comision Europea. (9 de Febrero de 2016). Gestion de la Crisis de los Refugiados: La comision informa sobre la aplicacion del Plan de accion conjunto UE-Turquia. (C. Europea, Ed.) Obtenido de COMISION EUROPEA: https://ec.europa.eu/commission/presscorner/detail/es/IP_16_268

De Miguel, B. (3 de diciembre de 2009). ¿Cúantas mezquitas hay en Europa? Obtenido de Cinco días:

https://cincodias.elpais.com/cincodias/2009/12/03/la_ue_del_reves/1259866194_1259 86.html 
El acceso al Derecho de la Union Europea. (11 de Diciembre de 2017). Tratado Constitutivo de la Comunidad Europea del Carbon y del Acero, Tratado CECA. Obtenido de El acceso al Derecho de la Union Europea: https://eur-lex.europa.eu/legalcontent/ES/TXT/?uri=LEGISSUM\%3Axy0022

EOM. (12 de Enero de 2020). El negocio de las redes migratorias en el norte de áfrica. Obtenido de https://elordenmundial.com/negocio-redes-migratorias-norte-africa/ Europa, G. d. (s.f.). Las migraciones en Europa. Obtenido de http://www.ub.edu/medame/TEMA2-2.pdf

Europapress.es. 2021. La OTAN y FRONTEX sellan acuerdo de cooperación contra las mafias y el tráfico irregular en el Egeo. Obtenido de https://www.europapress.es/internacional/noticia-otan-frontex-sellan-acuerdocooperacion-contra-mafias-trafico-irregular-egeo-20160306192010.html

Europea, C. (4 de Marzo de 2016). Web oficial de la UE. Obtenido de https://ec.europa.eu/commission/presscorner/detail/es/IP_16_585

Europea, D. o. (2007). Tratado de Lisboa. Obtenido de https://www.boe.es/doue/2007/306/Z00001-00271.pdf

Europea, D. o. (2016). Carta de los derechos fundamentales de la Unión Europea. Obtenido de https://eur-lex.europa.eu/legalcontent/ES/TXT/HTML/?uri=CELEX:12016P/TXT\&from=ES

Europea, T. c. (s.f.). Obtenido de http://ocw.uc3m.es/historia-del-derecho/historia-de-laintegracion-europea/tratados/Tratado_Cee.pdf/at_download/file

Europea, U. (1997). Tratado de Amsterdam. Obtenido de https://europa.eu/europeanunion/sites/europaeu/files/docs/body/treaty_of_amsterdam_es.pdf

Europea, U. (1997). Tratado de Amsterdam. Obtenido de https://europa.eu/europeanunion/sites/europaeu/files/docs/body/treaty_of_amsterdam_es.pdf 
Europea, C. d. (s.f.). Tratado de la Unión Europea. Obtenido de 1992:

https://europa.eu/european-

union/sites/europaeu/files/docs/body/treaty_on_european_union_es.pdf

FAO. (s.f.). Programa especial para la seguridad alimentaria (PESA) Centroamerica.

Obtenido de

http://www.fao.org/in-action/pesa-centroamerica/temas/conceptosbasicos/es/

Feliciano, T. (20 de mayo de 2016). Las familias de refugiados en la UE pagan 860 millones a las mafias para reunir parientes. Obtenido de Europol, Interpol https://www.bez.es/188079566/refugiados-dinero-mafias-familiasue.html

FRONTEX. (s.f.). Principales responsabilidades. Obtenido de https://frontex.europa.eu/es/que-hacemos/principales-responsabilidades/

Gamba, V. (27 de JULIO de 2018). Situación humanitaria. Obtenido de Noticias ONU: https://news.un.org/es/focus/siria

INFOBAE. (s.f.). Obtenido de https://www.infobae.com/2015/09/04/1753070-crisismigratoria-las-principales-rutas-llegada-europa/

Keohane, R. O. (1996). Después de la hegemonía. Obtenido de https://tri2ucv.files.wordpress.com/2013/02/despues-de-la-hegemonia-robert-okeohane.pdf

Mongenthau, H. J. (1985). Entre las naciones.

Mourenza, A. (28 de Noviembre de 2019). La factura europea de los refugiados en Turquía. Obtenido de El País: https://elpais.com/internacional/2019/11/21/actualidad/1574351046_331814.html 
OIM. (2006 de 2006). Glosario sobre Migracion. (R. Perruchoud, Ed.) Obtenido de ORGANIZACION INTERNACIONAL PARA LAS MIGRACIONES: https://publications.iom.int/system/files/pdf/iml_7_sp.pdf

ONU, C. d. (13 de Junio de 2018). Al menos 2,5 millones de migrantes fueron víctmas de las redes de tráfico. Obtenido de https://www.unodc.org/unodc/es/frontpage/2018/June/at-least-2-5-million-migrantswere-smuggled-in-2016--first-un-global-study-shows.html

ONU (Octubre 2018): Programa Mundial de Alimentos (PMA), Mapa del hambre de 2018, disponible en esta direccion: https://www.refworld.org.es/docid/5bcf99a44.html

Orgaz, J. C. (2018). Vox: Cómo es el primer partido de ultraderecha que llega a un parlamento en España en los últimos 36 años (y por qué genera polémica). Obtenido de BBC News Mundo: https://www.bbc.com/mundo/noticias-internacional-46434230

País, E. (6 de enero de 2017). Las rutas de entrada a Europa. Obtenido de https://elpais.com/elpais/2017/01/06/media/1483735640_540967.html

Ramos, V. (11 de marzo de 2019). Infografía del día: principales atentados Yihadistas en Europa desde 2015. Obtenido de EULIXE:

https://www.eulixe.com/articulo/imagen/infografia-del-dia-principales-atentadosyihadistas-en-europa-desde-2015/20190311110025010260.html

rights, S. O. (27 de marzo de 2019). Ocho años de guerra se cobran 370,000 vidas humanas en Siria. Obtenido de https://www.syriahr.com/en/122271/

RT. (10 de Febrero de 2017). La Union Europea trata de convertir a Libia en su propio muro anti-inmigrantes. Obtenido de RT: https://actualidad.rt.com/actualidad/230757-unioneuropea-convertir-libia-muro-refugiados 
Rubio, C. P. (s.f.). El concepto de refugiado en la convención sobre el estatuto de los refugiados de 1951: tratamiento normativo y realidad. Obtenido de file://C:/Users/Yuri\%20Mart\%C3\%ADnez/Downloads/7217Texto\%20del\%20art\%C3\%ADculo-28218-1-10-20130821\%20(1).pdf

Ruiz, B. A., \& Brunet, P. (septiembre de 2018). Levantando muros. Obtenido de Centre Delas dEstudis per la Pau: https://www.tni.org/files/publication-downloads/building_walls__full_report_spanish.pdf

Unidas, A. g. (10 de Diciembre de 1948). Declaración universal de los derechos. Obtenido de https://play.google.com/books/reader?id=TDBAQAAQBAJ\&hl=es\&pg=GBS.PP3.w.7.0.14

UNION EUROPEA. (9 de Mayo de 1950). Declaracion de Robert Schuman, 9 de mayo de 1950. Obtenido de UNION EUROPEA: https://europa.eu/european-union/abouteu/symbols/europe-day/schuman-declaration_es

Velasquez, C. C. (9 de Agosto de 2019). Entrevista.

Vial, R. I. (2017). El Sistema de Dublin. Obtenido de Repositorio Universidad de Chile: http://repositorio.uchile.cl/bitstream/handle/2250/144849/El-Sistema-deDubl\%C3\%ADn.pdf?sequence=1\&isAllowed $=\mathrm{y}$ 